\title{
"MY GOD!": A Feminist Critique of the Excited Utterance Exception to the Hearsay Rule $\dagger$
}

\author{
Aviva Orenstein $\ddagger$
}

\section{TABLE OF CONTENTS}

Introduction

I. The Traditional Definition and Defense of the Hearsay Rule

II. The Excited Utterance Exception: Nervous Agitation as a Guaranty of Spontaneity, Sincerity, and Reliability

A. A History of the Doctrine ......................................................168

B. The Current Doctrine...........................................................173

C. The Psychological Critique of the Excited Utterance Doctrine.

III. A Feminist Perspective

A. Difference, Dominance, and Evidentiary Objectivity

B. "He Said, She Said"-Toward a Feminist Critique of the Hearsay Rule

C. Considering the Rights of Criminal Defendants

Copyright (C 1997 Aviva Orenstein. Please do not quote or cite without the author's permission.

$\dagger$ Professor lrving Younger deridingly defined an excited utterance: "If it begins with the words 'My God!' then it is an excited utterance." Irving Younger, Hearsay: A Practical GuIDE Through THE THICKer 144 (1988).

$\ddagger \quad$ Associate Professor of Law, Indiana University School of Law-Bloomington. J.D. 1986, Cornell Law School. I am grateful for the summer research support from the Indiana University School of Law and for the comments I received in faculty workshops at Comell Law School and Indiana University School of Law. I also wish to thank my dear friends and colleagues for their enormous help and support. My appreciation goes to Judge Edward R. Becker, and Professors Naomi Cahn, Fred H. Cate, Kevin Clermont, Judy Cornett, Cathy Crosson, Roger Dworkin, Bruce Markell, Nancy Moore, Jeffery Rachlinski, Myma Raeder, Lauren Robel, Eleanor Swift, Alex Tanford, and Andrew Taszlitz for their encouragement and helpful comments on early drafts. Thanks also to Christine Zonkel for her patience in expertly typing multiple drafts, to Jennifer Mathews for her excellent work editing this piece for the California Law Review, and special thanks to David Greenberg, my best in-house editor. In particular, I wish to express my deep gratitude to Rabbi Debra Orenstein and Professors Kathryn Abrams, Lynne Henderson, and Susan Williams, whose intellectual generosity and critical engagement through multiple drafts improved this Article immeasurably. Obviously, any mistakes are entirely my own, owing, no doubt, to my failure to follow their good counsel. 
IV. That Same Old Voice is Yelling Again: A Feminist Critique of the Excited Utterance

A. The Myth of Universal Experience 198

B. Rape Trauma Syndrome and a Different Voice 199

C. Social Expectations of a Wronged Woman............................203

D. Denial and Power.............................................................205

E. Extending the Excited Utterance Doctrine .............................210

V. A Proposal for Amending the Excited Utterance Rule and for Establishing a New Hearsay Exception for Survivors of Rape and Other Sexual Violence.

A. Doctrinal Changes ...........................................................213

B. The Survivor's Statement..................................................215

C. The Practical Effect of the Survivor's Statement ...................220

Conclusion 


\title{
"MY GOD!": A Femmist Critique of the Excited Utterance Exception te the Hearsay Rule
}

\author{
Aviva Orenstein
}

The excited utterance exception admits hearsay statements made while the declarant was under the stress or excitement of a particularly startling event, on the theory that such stress or excitement precludes the kind of reflection necessary for the declarant to fabricate, and hence renders such out-of-court statements sufficiently reliable. The excited utterance exception has long been subjected to a psychological critique, which questions the wisdom of a doctrine that relies on the stress of the declarant. This criticism claims that stress and excitement are as likely to cloud perception and memory as they are to ensure truthfulness. The author applies the insights of both the difference and dominance schools of feminist jurisprudence to explain the longevity and cultural appeal of the doctrine in the face of such challenges. She criticizes the existing excited utterance exception on the ground that it betrays a masculine bias, privileging the accustomed responses to stress of empowered persons over those of women and other disadvantaged groups. The excited utterance exception ignores the experiences of people who deviate from the rule's paradigm of how "normal" people react to stress, and thereby subtly perpetuates a cultural and legal image of women as unreliable. In particular, the Article focuses on the inconsistency between the doctrinal demands of the excited utterance and women's documented reactions to rape. In requiring a prompt statement and visible signs of distress, the excited utterance exception simply does not reflect the reported experiences of many rape survivors who often are too disoriented, numb, afraid, or ashamed to issue a prompt statement, excited or otherwise. Instead, the excited utterance exception seems to describe best those who are sufficiently confident of their power to emit a prompt excited cry, and who expect.that their cries will be taken seriously. In response, the author proposes a modification of the excited utterance exception, and an additional exception that would allow out-of-court statements by survivors of sexual violence even when made well after the attack itself. The author incorporates safeguards to protect the rights of criminal defendants when such statements are to be introduced. 


\section{INTRODUCTION}

Evidence law is ideally suited for feminist analysis. This area of law regulates and reflects the construction of courtroom "truth." It perpetuates the cultural values, legal rules, and social norms that our society uses to assess credibility. ${ }^{1}$ On a more practical, doctrinal level, evidence law controls who will be heard. Essentially, evidence law governs how legal stories are presented and influences which stories are believed.

Feminist method offers a fascinating perspective on evidence law, because feminism, like evidence, is concerned with hov stories are heard and how society determines credibility. Feminist method seeks to uncover unconscious assumptions embedded in law and to examine how purportedly neutral rules may discriminate against women. ${ }^{2}$ This method also facilitates examination of the often unarticulated theories of relevance and reliability underlying evidence law.

This Article uses a feminist method to analyze the excited utterance doctrine, a codified exception to the hearsay rule in evidence law. ${ }^{3}$ In particular, the Article explores how the practical effects of the doctrine can be devastating for prosecutions of rape and other sexual crimes. The current limitations of the excited utterance exception sharply curtail

1. See Barbara J. Shapiro, "Beyond Reasonable Doubt" and "Probable Cause": Historical Perspectives on the anglo-American law of Evidence 2 (1991) (explaining that evidence law reflects "the culture's general understanding of how we 'know' things to be true").

2. As feminist methods for examining law have developed, scholars lave increasingly focused feminist critiques on purportedly "nentral" areas of law. Various traditional legal disciplines such as torts and civil procedure have joined family law, rape, and sexual harassment as topics of feminist concern. See, e.g., Leslie Bender, An Overview of Feminist Torts Scholarship, 78 CoRnell L. Rev. 575 (1993); Judith Resnik, "Naturally" Without Gender: Women, Jurisdiction, and the Federal Courts, 66 N.Y.U.L. REv. 1682 (1991) (examining the roles of wonien in federal court and the role of gender in federal jurisdiction); Elizabeth M. Schneider, Gendering and Engendering Process, 61 U. CIN. L REv. 1223, 1223 n.3, $1224 \mathrm{nn} .4$ \& 6, 1231-32 (1993) (listing articles about feminism and procedure and noting that "feminist concern with process can assist us to explore a richer, more focused, complex and contextual analysis of the role of process").

Initial groundwork has been laid in applying fcminism to evidence law generally. See Aviva Orenstein, Feminism \& Evidence, in Feminist Jurisprudence, WOMEn and the Law: Critical EsSAYs, Research AGENDA AND Bibliography (Sharon Rush et al. eds., forthcoming 1997) (exploring possible connections between feuninism and evidence); Ann Althouse, The Lying Woman, the Devious Prostitute, and Other Stories From the Evidence Casebook, 88 Nw. U. L. REv. 914 (1994) (reviewing evidence casebooks for gender bias); Rosemary C. Hunter, Gender in Evidence: Masculine Norms vs. Feminist Reforms, 19 HARv. WoMEN's L.J. 127 (1996) (analyzing the effects of gender on questions of credibility and relevance); Kit Kinports, Evidence Engendered, 1991 U. IL. L. REv. 413 (explaining ways evidence law might learn froin feminist jurisprudence); Marilyn MacCrimmon, The Social Construction of Reality and the Rules of Evidence, 25 U. BRIT. CoLUM. L REv. 36 (1991).

3. The excited utterance exception admits out-of-court statements "relating to a startling event or condition made while the declarant was under the stress of excitement caused by the event or condition." FED. R. EvID. 803(2). These statements are substantive evidence admitted for the truth of the matter asserted by the declarant. The declarant need not testify, even though she is available as a witness. FED. R. Evid. 803. 
the chances for survivors of rape or other sexual violence to tell their stories truthfully, completely, and in their own words. By requiring a prompt utterance and visible signs of distress, the excited utterance exception fails to reflect the reported experiences of rape survivors, who often are too disoriented, numb, afraid, or ashamed to issue a prompt statement, excited or otherwise.

In charting the misfit between the doctrine and the reported experiences of women subjected to rape and other sexual violence, the Article examines how the excited utterance doctrine may perpetuate a legal and cultural image of women as unreliable. To remedy this disjuncture between the excited utterance exception and the experiences of sexual violence survivors, the Article proposes a new hearsay exception targeted to survivors of sexual violence.

Part I of this Article describes the hearsay rule and its traditional rationale. Part II traces the doctrinal history of the excited utterance exception, which admits out-of-court statements concerning a startling event made while the declarant is still under the stress of the event. Part II also summarizes the standard psychological critique of the excited utterance exception. This critique postulates that the declarant's stress, a necessary element of the excited utterance exception, may distort the declarant's perception and memory, thereby diminishing the declarant's reliability and discrediting the rationale of the excited utterance doctrine.

The Article next develops and applies a feminist analysis to the excited utterance exception. Part III draws on two strands of feminism, difference and dominance feminism. Applying theories from these two schools of feminism, the Article assails the structure and philosophy of the hearsay rule, concluding that it both reinforces hierarchical relations in the courtroom and disfavors certain speakers and styles of communication. Specifically, Part III argues that the hearsay ban tends to exclude women's styles of communication, which have traditionally emphasized informality and privacy. Despite this criticism, however, the Article does not advocate eliminating the hearsay rule, because of concern for the rights of criminal defendants, particularly the right to confront wituesses.

Part IV subjects the excited utterance exception to a feminist critique in the context of survivors of rape and other sexual violence. In particular, the Article focuses on the disjuncture between the doctrinal demands of the excited utterance exception-an excited cry issued near the time of the startling event-and women's documented reactions to rape and other sexual violence. This problem is exacerbated by the fact that although courts are unpredictable in their determinations of the timing requirements for admissibility of excited utterances, many will 
often exclude survivors' statements if they do not fall within narrow time constraints. The strict adherence to timing requirements is particularly troubling where the excited utterer is unavailable because she was killed or intimidated by her attacker. Even where the survivor is available to testify, however, the excited utterance rule is problematic, excluding hearsay statements that may provide increased information and context, particularly where the survivor is traumatized, embarrassed, or is otherwise a reticent witness.

Part IV argues that the excited utterance exception stems from overly narrow and gendered assumptions of how "normal" people react to stress. Additionally, the Article observes that the cultural stereotypes embedded in the excited utterance doctrine reflect the experience and world view of those who possess power, and who, by extension, are confident enough to emit a prompt excited cry and expect it to be taken seriously. The excited utterance doctrine excludes certain reliable but less powerful speakers, thereby contributing to a legal climate that discredits, among others, many women. ${ }^{4}$

To remedy the underinclusive natnre of the excited utterance exception, Part $\mathrm{V}$ proposes a new hearsay exception that targets survivors of sexual violence. ${ }^{5}$ The proposal would apply to all survivors of sexual crimes, not just women. Because of trauma, fear, lack of power, shame, or even reticent conversational style, such survivors may not make prompt statements or exhibit external, culturally recognized signs of stress. For this reason, the proposal would admit extra-judicial statements made by survivors into evidence without regard to the length of delay between the traumatic event and the survivor's statement. Additionally, the proposal eliminates the requirement that the speaker manifest or experience stress when making the utterance.

4. This theory extends to other disempowered groups and therefore calls for further scholarship and exploration of this effect. See infra Part IV.E (calling for extension of the excited utterance doctrine).

5. This Article uses the term "survivor" rather than "victim" to refer to someone who has experienced sexual violence. This choice reflects an attempt to avoid the stigma of victimization and to honor the people who survive the ordeal of rape. See Martha R. Mahoney, Exit: Power and the Idea of Leaving in Love, Work, and the Confirmation Hearings, 65 S. CAL. L. REv. 1283, 1310-11 \& n.I I5 (1992) (explaining that "survivor" has replaced "victim" in feminist vocabulary to refute the notion that the woman in rape and battering situations is passive); Evelyn Mary Aswad, Note, Torture by Means of Rape, 84 GEo. L.J. 1913, $1916 \mathrm{n} .11$ (1996) (explaining the use of the term rape "survivor" to "eliminate the victim role") (quoting Metin Basoglu, Prevention of Torture and Care of Survivors, 270 JAMA 606, 606 (1993)). This terminology is not without its critics, who bclieve that avoidance of the term "victim" is unfair and may in some way blame women or ignore the feeling of being a victim. See, e.g., Kate E. Bloch, A Rape Law Pedagogy, 7 YALE J.L. \& FEMINISM 307, 308 n.6 (1995) (using "the term rape 'survivor' reluctantly" because of respect for the feelings of victimization of people who have been raped). Unfortunately, this terminology becomes awkward when the rape "survivor" literally does not survive and dies of her rape-related injuries. 
The proposed exception also reflects a concern for the rights of criminal defendants. It requires, where possible, that defendants be presented with an opportunity to cross examine declarants of excited utterances or survivors' statements. Where the declarant is unavailable, the proposal requires a particularized showing of trustworthiness. These and other safeguards guarantee that the interests of criminal defendants will not be sacrificed in fashioning a hearsay exception that acknowledges and includes the experience of women and other survivors of sexrelated crimes.

I

The Traditional Definition and Defense of the HEARSAY RULE

The hearsay rule provides that out-of-court statements may not be used for the truth of the matter asserted. ${ }^{6}$ A party cannot introduce a statement made outside the trial to persuade the trier of fact that the statement is substantively true.?

The most prevalent modern theory explaining the hearsay rule holds that the rules of evidence in general, and hearsay in particular, track the development of the jury system. Over time, the jury has shifted from a group of neighbors with personal knowledge of the events at issue to an impartial fact-finding group that relies on partygenerated evidence. ${ }^{8}$ A combination of paternalism and distrust of jurors prompted courts to exclude from the jury's consideration categories of evidence deemed unreliable. ${ }^{9}$ The most important exclusion was

6. See Ohio v. Roberts, 448 U.S. 56, 62 n.4 (1980) (relying on McCormick's definition of hearsay as "testimony in court, or written evidence, of a statement made out of court, the statement being offered as an assertion to show the truth of matters asserted therein, and thus resting for its value upon the credibility of the out-of-court asserter").

7. The hearsay rule presents many puzzles. The first, and arguably hardest, intellectual step is to identify hearsay. For instance, courts and scholars have pondered the nature of an out-of-court "statement" and whether assertions must be intentional. See, e.g., Roger C. Park, "I Didn't Tell Them Anything About You": Implied Assertions as Hearsay Under the Federal Rules of Evidence, 74 MiNN. L. REv. 783 (1990) (examining treatment of implied assertions under moderu caselaw); Glen Weissenberger, Hearsay Puzzles: An Essay on Federal Evidence Rule 803(3), 64 TEMP. L. REv. 145 (1991); see also MCCORMICK ON EvIDENCE §§ 244, 246 (John William Strong ed., 4th ed. 1992) [hereinafter McCoRMick].

8. See McCormick, supra note 7, § 244 (discussing the relationship between the development of the jury and hearsay law); James Bradley Thayer, A Preliminary Treatise on Evidence at the Common Law 519 (1898). See generally John Marshall Mitnick, From Neighbor-Witness to Judge of Proofs: The Transformation of the English Civil Juror, 32 AM. J. LEGAL Hist. 201, 203-12 (1988).

9. See Dale A. Nance, The Best Evidence Principle, 73 IowA L. Rev. 227, 293 (1988) (disagreeing with the "long-prevailing jury distrust model of evidence law"); id. at 229-30; Roger Park, A Subject Matter Approach to Hearsay Reform, 86 Mich. L. Rev. 51, 60 n.37 (1987) ("[B]ecause of distrust of juries-a belief that jurors lack the competence to make allowance for the second-hand character of hearsay-such evidence, although accepted by administrative agencies, 
hearsay. Courts consider jurors too unsophisticated and gullible to weigh hearsay appropriately. ${ }^{10}$

What is it about hearsay that can trigger a juror's irrationality or poor judgment? Traditionally, evidence law excluded hearsay because it lacked the following characteristics: assurances of reliability stemming from an in-court oath, ${ }^{11}$ the ability of the factfinder to observe witness demeanor, ${ }^{12}$ the possibility of prosecution of the declarant for perjury, and, most importantly, the opportunity for cross-examination. ${ }^{13}$

For instance, imagine that an in-court witness wants to testify that an absent declarant, Dora, exclaimed near the scene of an accident, "The car ran the red light!" The hearsay rule requires Dora's direct testimony, rather than a report from another witness about what Dora said. Even if the witness to Dora's declaration were truthful in his re-

juvenile courts and legislative committees, is (subject to be sure, to numerous exceptions) barred in jury trials.") (quoting J. Frank, Courts on TrIal 123 (1949)); L. Timothy Perrin, Expert Witness Testimony: Back to the Future, 29 U. RICH. L. Rev. 1389, 1425 n.210 (1995) (citing Jones on Evidence and THAYER, supra note 8 for the jury mistrust theory of hearsay); Eleanor Swift, Abolishing the Hearsay Rule, 75 CALIF. L. REv. 495, 496 n.2 (1987) (noting that "most commentators see the hearsay rule as a child of the jury, a tool for judicial protection against inaccurate factfinding").

10. A second theory, the "best evidence principle," has been recently revived by Professor Dale Nance. See Nance, supra note 9 (arguing that the overarching principle of evidence law is securing the best reasonably obtained evidence); see also Edward J. Imwinkelried, The Worst Evidence Principle: The Best Hypothesis as to the Logical Structure of Evidence Law, 46 U. MIAMI L. REv. 1069 (1992) (rejecting the jury-focused approach and arguing that evidence law revolves around avoiding untrustworthy evidence and witnesses-the worst evidence-rather than affirmatively seeking the best evidence).

11. There is debate about the efficacy of the oath in an age that has rejected divine retribution. Wigmore argued that the oath was non-essential, because out-of-court statements, even when sworn, were not admissible for their hearsay purpose. See 5 JOHN HENRY WIGMORE, Evidence IN TRIALS AT THE CoMmon LAw $\S 1362$ (James H. Chadbourn ed., 1978). McCornick argues persuasively, however, that the oath has some vestigial impact by adding to the solemnity and majesty of the proceedings. See McCormick, supra note 7, § 245.

12. Evidence law encourages in-court testimony and disfavors out-of-court statements. See Olin Guy Wellborn IIl, Demeanor, 76 CoRnell L. Rev. 1075, 1076 (I991) (noting the law's preference for demeanor evidence, but questioning its effectiveness in determining whether a witness is lying).

13. See, e.g., Donnelly v. United States, 228 U.S. 243, 273 (1913) (explaining that hearsay is generally unreliable because it lacks protections of oath, demeanor observation, and cross. examination). Lest this be the only evidence law review article in history to discuss crossexamination without trotting out Wigmore's famous dictum, here it is: Wigmore described crossexamination as "beyond any doubt the greatest legal engine ever invented for the discovery of truth." WIGMORE, supra note $11, \S 1367$, at 32 .

There are many other explanations for and reformulations of the hearsay rule aside from the traditional fretting over accuracy and concern for cross-examination. The hearsay rule must be understood, at least in part, as an outgrowth of the adversary system. For all the coneerns about accuracy, reliability, and jury confusion, hearsay is almost entirely party driven. Generally, if the parties fail to object, the hearsay is in. See McCormick, supra note 7, § 245.

In addition, the hearsay rule can be seen as a mechanism for preventing the government and large corporations from manufacturing reams of documents to deluge opponents who lack resources. See Park, supra note 9, at 65-66. 
port, ${ }^{14}$ information could get lost in the translation or repetition. Dora could have been joking or lying. Something could have obstructed her view. She could be colorblind. Too much time might have elapsed since the car passed for Dora to remember. The witness could have misheard Dora. These concerns regarding sincerity, narration, perception, and memory form the core of the traditional preference for incourt testimony.

Although these "hearsay dangers" are also present in live testimony, they are diminished by the availability of cross-examination. Cross-examination is designed to uncover weaknesses in Dora's account. These weakness might be impossible to detect without Dora herself, rather than a reporting hearsay witness, on the stand. ${ }^{15}$

Of course, one cannot comprehend the scope of hearsay without inquiry into its many exceptions. ${ }^{16}$ What characteristics make evidence admitted pursuant to these exceptions preferable to requiring live, incourt testimony or to excluding the evidence altogether? Although there are various justifications for the different exceptions, ${ }^{17}$ many hearsay exceptions are chiefly explained by the presumed trustworthiness of the statements they admit. The law of evidence has established categories of statements for which the traditional concern with sincerity is offset by some presumed guarantee of reliability. For instance, courts justify the declaration-against-interest exception because of its purported reliability. ${ }^{18}$ The declaration-against-interest exception admits out-of-court statements that are contrary to the speaker's pecuniary interest for the truth of the matter asserted. This exception arose from the

14. This factor can be tested insofar as it is possible to detect lies and liars on crossexamination, because the reporting witness does testify in court.

15. See McCormick, supra note 7, $\$ 245$ (discussing reasons for the rule against hearsay); Laurence H. Tribe, Triangulating Hearsay, 87 HARv. L. REv. 957, 958 (1974).

16. The exceptions are so vast, they arguably swallow the rule, as Professor James Bradley Thayer wrote:

But then comes the question, what is the rule, and what are the exceptions? There lies a difficulty. A true analysis would probably restate the law so as to make what we call the hearsay rule the exception, and make our main rule this, namely, that whatsoever is relevant is admissible.

THAYER, supra note 8, at 522. Similarly, a more modern commentator has observed, "In the sea of admitted hearsay, the rule excluding hearsay is a small and lonely island." Jack B. Weinstein, Probative Force of Hearsay, 46 IowA L. REv. 331, 346 (1961); see I. Daniel Stewart, Jr., Perception, Memory, and Hearsay: A Criticism of Present Law and the Proposed Federal Rules of Evidence, 1970 UTAH L. REv. 1, 7 (noting that "numerous exceptions largely subsume the general rule").

17. Justifications for exceptions include necessity, see, e.g., FED. R. EvID $801(\mathrm{~d})(2)(\mathrm{E})$ (excepting from the hearsay rule co-conspirators' statements made during and in furtherance of the conspiracy), and the adversary system, see FED. R. Evid. 801(d)(2)(A) (excepting personal admissions from the hearsay rule). Certainly, no coherent unifying theory explains the "crazy quilt" of hearsay exceptions.

18. Fed. R. Evid. 804(b)(3). This hearsay exception can only be used if the declarant is unavailable to testify. Although I discuss declarations contrary to pecuniary interest, the exception is not limited to such interests. 
presumption that people rarely make statements contrary to their financial interest; therefore, such statements are particularly trustworthy.

Similarly, the admissibility of an excited utterance is justified by the purported trustworthiness of such statements. The excited utterance exception relies on the theory that the nervous excitement experienced by the utterer leads to spontaneity, which in turn guarantees reliability. However, as the Part II.C demonstrates, many psychologists as well as legal scholars point to persuasive evidence that reliability does not invariably follow from spontaneity, and that nervous excitement can lead to confusion and failure of perception.

II

\section{The Excited Utterance Exception: Nervous Agitation as a GUARANTY OF SPONTANEITY, SINCERITY, AND RELIABILITY}

\section{A. A History of the Doctrine}

The excited utterance exception derives from res gestae, which literally means "things done" or "things happened." Many modern evidence concepts have evolved from the concept of res gestae. According to McCormick, courts began to employ the term in the early 1800 s to include spontaneous declarations that accompanied legally relevant acts. ${ }^{20}$ Res gestae includes elements that fall outside the modern hearsay definition altogether, such as circumstantial evidence of state of mind, so-called "verbal acts," verbal parts of acts, and certain nonverbal conduct. Because excited utterances are connected closely in time to the event and the excitement flows from the event, excited utterances were deemed part of the action (the "things done") and hence

19. The concept refers to "words spoken, thoughts expressed, and gestures made... so closely connected to occurrence or event in both time and substance as to be a part of the happening." Black's Law Dictionary 1305 (6th ed. 1990). Res gestae are the "automatic and undesigned incidents of the particular act in issue ...." Keefe v. State, 72 P.2d 425, 427 (Ariz. 1937). Although courts still occasionally employ the term res gestae, it is for the most part a relic that served as a transitional device in the evolution of various hearsay exceptions. See McCormick, supra note $7, \S$ 268.

Res gestae captured the interest and inspired the ire of many evidence greats. Sir Frederick Pollack called it a "damnable pretended doctrine." Letter from Sir Frederick Pollock to Oliver Wendell Holmes, Jr. (Apr. 23, 1931), in 2 Holmes-Pollock LetTers 284 (Mark DeWolfe Howe ed., 2d ed. 1941). Edmund M. Morgan began his classic article, A Suggested Classification of Utterances Admissible as Res Gestae, 31 YALE LJ. 229 (1922), by noting that "[t]he marvelous capacity of a Latin phrase to serve as a substitute for reasoning ... [is] nowhere better illustrated than in the decisions dealing with the admissibility of evidence as 'res gestae." Id. at 229. Learned Hand remarked, "... as for 'res gestae,' it is a phrase which has been accountable for so much confusion that it had best be denied any place whatever in legal terminology; if it means anything but an unwillingness to think at all, what it covers cannot be put in less intelligible terms." United States v. Matot, 146 F.2d 197, 198 (2d Cir. 1944).

20. See McCoRMICK, supra note $7, \S 268$. These statements fall outside the hearsay definition because they do not demand that the factfinder believe that the statements are actually true, but only that they were made. See FED. R. Evid. 801(c) advisory committee's note. 
admissible despite the hearsay rule. Res gestae also sired the hearsay exceptions for present-sense impressions, excited utterances, direct evidence of state of mind, and statements made to physicians. ${ }^{21}$

The excited utterance exception provides that statements made under the mfluence of an exciting event while the speaker is still in a state of nervous excitement may be admitted for the truth of the matters they assert. This exception was isolated and promoted by John Henry Wigmore. ${ }^{22}$ In his multi-volume treatise on evidence, Wigmore developed in intricate detail what he termed the "spontaneous exclamation" exception to hearsay, which we recognize today as the excited utterance exception. According to Wigmore, a hearsay statement must meet the following criteria to qualify under this exception: (1) there must be a "startling occasion," (2) the out-of-court statement must be made before the declarant has had time to "fabricate," and (3) the declarant's out-of-court statement must relate to the circumstances of the startling event. ${ }^{23}$

Wigmore explained the policy of the exception as follows:

This general principle is based on the experience that, under certain external circumstances of physical shock, a stress of nervous excitement may be produced which stills the reflective faculties and removes their control, so that the utterance which then occurs is a spontaneous and sincere response to the actual sensations and perceptions already produced by the external shock. $^{24}$

21. See Eleanor Swift, The Hearsay Rule at Work: Has it Been Abolished De Facto by Judicial Decision?, 76 MINN. L. REV. 473, 475 (1992).

22. See 4 Jack B. Weinstein \& Margaret A. Berger, Weinstein's Evidence I 803(2)[01][D], at 803-85 (discussing excited utterance exception and noting that it was "deducted initially by Wigmore"); James Donald Moorehead, Compromising the Hearsay Rule: The Fallacy of Res Gestae Reliability, 29 LoY. L.A. L. REv. 203, 232 (1995) ("The exception for excited utterance may be traced directly to Wigmore's belief' that stress leads to sincerity.); Park, supra note 9, at 76 n.100 (1987) (discussing how the doctrine of res gestae evolved "with Wigmore's help" into the excited utterance exception).

23. 6 Wigmore, supra note $11, \S 1750$, at 202 . The modern rule tracks all three requirements. See Fed. R. Evid. 803(2); infra notes $41-43$ and accompanying text.

24. 6 WIGMORE, supra note $11, \S 1747$, at 195 . In another section, Wigmore similarly explained that "in the stress of nervous excitement the reflective faculties may be stilled and the utterance may become the unreflecting and sincere expression of one's actual impressions and belief." Id. § 1749, at 199. More modern scholarship has echoed this reasoning, noting that the exciting event "leaves the speaker momentarily incapable of fabrication, and his memory is fresh because the impression has not yet passed from his mind." Christopher B. MUELlER \& LAIRD C. KIRKPATRICK, EvIDENCE $\S 8.35$, at 1217 (1995) (noting that "[i]n short, risks of insincerity and memory lapse are removed"); see also Glen Weissenberger, Federal Evidence $\$ 803.7$, at 440 (2d ed. 1995) ("Statements made in reaction to a startling stimulus are considered more trustworthy than hearsay generally on the dual grounds that, first, the stimulus renders the declarant incapable of fabrication and, second, the impression on the declarant's memory at the time of the statement is still fresh and intense."). 
The witness' state of nervous tension was of utmost importance in Wigmore's analysis. According to Wigmore, this "immediate and uncontrolled domination of the senses" lasts for a "brief period."25 During this short time, neither thoughts of "self-interest" nor other "reasoned reflection" arise..$^{26}$ Therefore, the utterance is "particularly trustworthy" and may be admitted despite its hearsay character. ${ }^{27}$ Wigmore even hinted that such evidence is superior to in-court testimony because of its spontaneity and closeness to the event. ${ }^{28}$

Wigmore traced the excited utterance doctrine back to Thompson $v$. Trevanion, decided by Lord Holt in $1693 .^{29}$ In Thompson, the court permitted the out-of-court declaration of the wife of the plaintiff (she could not sue on her own behalf) "immediately [sic] upon the Hurt received, and before that she had Time to devise or contrive any Thing for

25. 6 WIGMORE, supra note $11, \S 1747$, at 195 . It is interesting to speculate how Wigmore, whose intellectual maturity coincided with the arrival of psychoanalytic theory in America, might have been influenced by the growth of Freudian psychology. The psychoanalytic insight that emotions sometimes affect mental function, intellect, and perception supports Wigmore's theory that stress stills reflection.

26. Id.

27. Id. Similarly, in 1929 Edmund Morgan described a hearsay exception relating to "spontaneous" utterance. See generally Morgan, supra note 19. Such an utterance concerns "a startling event" made "by a declarant laboring under such a stress of nervous excitement, caused by that event, as to make such utterance spontaneous and unreflective." Id. at 238. This spontaneous utterance was admissible in many courts despite its hearsay status. See id. According to Morgan, the declaration was likely to be trustworthy because "the mental condition of the declarant is such that the probability of his being able to devise a falsehood is very remote." Id. at 239.

28. 6 WIGMORE, supra note $11, \S 1749$, at 199 (discussing "the superior trustworthiness" of the out-of-court statements as "creating a necessity or at least a desirability of resorting to them for unbiased testimony"). See generally W.A. Harrington, Annotation, Time Element as Affecting Admissibility of Statement or Complaint Made by Victim of Sex Crime as Res Gestae, Spontaneous Exclamation, or Excited Utterance, 89 A.L.R.3d I02 (I979) (Supp. 1996) (organizing excited utterance cases by lapse of time). Furthermore, Wigmore argued that the exception requircd no principle of necessity to be admissible; neither death nor other reasons for absence of the witness need be shown to admit the spontancous exclamation. See 6 WIGMORE, supra note $11, \S 1748$. Wigmore was adamant that bystander declarations should be admissible so long as the bystander was under the stress of nervous excitement. See id. $\S 1750$, at 202-03. Moreover, he believed that insanity, criminality, and infancy did not disqualify a declarant. See id. § 1751; see also MCCORMICK, supra note 7, $\S 272$, at 476 ("The declarant need not actually be involved in the event; an excited utterance by a bystander is admissible."); Quick, supra note 22, at 213 (discussing the issuc of competence and excited utterance). Wigmore observed that the primary objection to the testimony of children-that they would not understand the solemnity of the oath-did not apply in the excited utterance setting where none of the declarations were made under oath anyway. See 6 WIGMORE, supra note $11, \S 1751$, at 223 .

29. See id. $\$ 1747$, at 196 (citing Skinner 402 (1693)). Here is the opinion in full: Ruled upon Evidence, that a Mayhem may be given in Evidence, in an Action of Trespass of Assault, Battery, and Wounding, as an Evidence of Wounding per Holt Chief Justice; and in this Case he also allowed, that what the Wife said immediate upon the Hurt receivcd, and before that she had Time to devise or contrive any Thing for her own Advantage, might be given in Evidence; Quod nota; this was at Nisi prius in Middlesex for wounding of the Wife of the Plaintiff.

Thompson v. Trevanion, Skinner 402 (1693). 
her own Advantage ...."30 Interestingly, the case that, according to Wigmore, established the excited utterance is ambiguous. It is unclear from the very brief text whether the declaration was reliable because the wife was excited or because her cry was immediate, or perhaps both.

Wigmore postulated that precise contemporaneousness was not required to meet the excited utterance exception and believed that the doctrine did not have a fixed time limit between startling event and excited utterance. He disdained the timing issue and decried the "lamentable waste of time" expended by various state high courts trying to pin down precise temporal limits for the doctrine's application. ${ }^{31}$ He believed that duration of stress, rather than exact timing, played the predominant role justifying this exception to the hearsay rule. ${ }^{32}$

For this reason, Wigmore derided a famous, early, and contentiously debated ${ }^{33}$ English case, Regina $v$. Bedingfield, ${ }^{34}$ for adhering to

30. Id. (emphasis added).

31. 6 WIGmore, supra note $11, \S 1750$, at 221 . Wigmore contended that all such judgments were contextual and to try to establish a general rule on the time limit "is to trifle with principle and to cumber the records with unnecessary and unprofltable quibbles." Id. Ironically, the timing question, and all the quibbling it entails, represents a controversial part of the doctrine today and serves as the basis of many (unsuccessful) appeals of criminal convictions. See infra notes 58-61 and accompanying text.

32. There is a strong argument that in "restating" the common law, Wigmore overstated the entrenchment of the excited utterance doctrine within the common law. Wigmore advocated the excited utterance as the true descendant of the res gestae concept and rejected the present sense impression (which requires almost contemporaneous utterance, but does not require a stressful event). See 6 Wigmore, supra note 11, § 1750; see also Moorehead, supra note 22, at 230 ("In contrast with his support of the excited utterance exception, Wigmore opposed the exception for present sense impression ...."). In justifying the admission of these startling statements, Wigmore emphasized the confusion caused by the startling event, but undervalued the traditional requirement of closeness in time. He failed to appreciate that the continuous agitation of mind was not in itself traditionally considered a guarantee of trustworthiness, but rather the stress was a proxy for a briefness in time. This confusion is reflected in his interpretation of Thompson $v$. Trevanion, in which Wigmore stressed the excitement but ignored the related timing question; that the statement was said "immediate upon the Hurt received." See 6 Wigmore, supra note 11, §§ 1747, 1749.

Additionally, Wigmore's scholarship is subject to criticism for his mischaracterization of the Supreme Court's decision in Travellers' Insurance Co. v. Mosley, 75 U.S. (8 Wall.) 397 (1869). The Court in Travellers' emphasized the connection in time and place between the utterance and the central fact in the case, rather than the exciting quality of the event. See id. at 408; 6 WIGMORE, supra note $11, \S 1747$. Wigmore was similarly unforthright in his comment on Vicksburg \& Meridian Railroad v. O'Brien, 119 U.S. 99 (1886), where he quoted with approval from Justice Field's dissent, stressing the excited nature of the out-of-court statement, but made no mention of the majority opinion (and gave no indication that Field wrote in dissent). See 6 WIGMORE supra note 11, 1749 . Also in his Vicksburg discussion, Wigmore, in advocating the excited utterance exception, redacted the Supreme Court opinion to edit out favorable remarks about Greenleaf, another treatise writer with whom Wigmore disagreed. See id.

33. For those who think that backbiting scholarly commentary and media hype of sensational trials are a modem phenomenon, Thayer's three-part article on the Bedingfield case will quickly disabuse them of their misplaced nostalgia. The Chief Judge of England responded with acrimony when his opinion in Bedingfield was criticized in the London Times. The Chief Judge issued pamphlets and newspaper editorials mocking Greenleaf and Taylor, two evidence Iuminaries who had publicly criticized the opinion. Taylor responded in kind, arguing that the Chief Justice's attack 
a rigid rule of contemporaneousness. In Bedingfield, an English Court excluded an utterance made only moments after a startling attack. ${ }^{35}$ The prosecutor wished to tell the jury in his opening statement that the victim had said before dying, "O aunt, see what Bedingfield has done to me. ${ }^{36}$ According to the court, her cry did not qualify as res gestae because "it was something stated by her after it was all over . . .".37 Lord Cockburn drew the distinction between a statement "uttered by the deceased at the time the act was being done" and a statement uttered "after the act was completed."38 Lord Cockburn explained that had the victim cried, "Don't, Harry!" while the violence transpired, her statement would have been admissible. ${ }^{39}$ Wigmore criticized the Bedingfield court's strict adherence to timing, arguing that it led to troubling, even absurd, results. ${ }^{40}$ Instead, Wigmore emphasized the startling nature of

was "neither consistent with your dignity, your generosity, nor your justice ...." James B. Thayer, Bedingfield's Case: Declarations as a Part of the Res Gesta (Pt. 1), 14 AM. L. REv. 817, 823-24 (1880) [hereinafter Thayer, Bedingfield $\Pi$. Thayer himself was not above an acerbic remark, noting of the phrase res gestae, "We find it first in the mouths of Garrow and Lord Kenyon,-two famously ignorant men." James B. Thayer, Bedingfield's Case, Declarations as a Part of the Res Gesta (Pt. II), 15 AM. L. REv. 1, 10 n.1 (1881).

34. 14 Cox Crim. Cas. 341 (1879).

35. Henry Bedingfield was charged with killing his lover who, according to the court, had "refus[ed] him something he very much desired" and appeared to "wish to put an end to these relations." See id. at 341 . Bedingfield had made prior threats to slit the victim's throat and she had asked for police protection. See id. at 341-42. After visiting a "spirit shop," Bedingfield went to her house (which was also her place of business). Id. at 342. After a "minute or two the [woman] came suddenly out of the house towards [her assistants] with her throat cut, and on meeting one of them she said something, pointing backwards to the house. In a few minutes she was dead." Id. The defendant was found with his throat cut as well, but he recovered and was charged with murder. He pled not guilty, arguing that the woman attacked him and then took her own life. See id. at 344 . Evidence of the knife in the defendant's bloody grasp, the decp cut in her throat inconsistent with suicide, and the fact (not content) of the victim's complaint, however, led to the guilty verdict. See id. at 344-45. It is also remarkable how closely the facts of the Bedingfield case fit the tragically familiar pattern of a battered woman killed by her lover: an abusive mate, alcohol, failure to receive police protection, and death at the hands of the abuser when the woman tries to leave.

36. See Thayer, Bedingfield 1, supra note 33, at 826.

37. Bedingfield, $14 \mathrm{Cox}$ Crim. Cas. at 342-43. Although Bedingficld was found guilty and sentenced to death by hanging, a serious outcry in the press and among scholars arose out of Lord Cockburn's exclusion of the woman's remark as falling outside the res gestae exception. See Thayer, Bedingfield I, supra note 33, at 819-20. Lord Chief Justice Cockburn also held that the deceased's statement did not qualify as a dying declaration, because there was no evidence that the victim knew she was dying. See Bedingfield, 14 Cox Crim. Cas. at 343-44. Cf. FED. R. Evid. 804(b)(2) (providing exception to the hearsay rule for statements "made by a declarant while believing that the declarant's death was imminent, concerning the cause or circumstances of what the declarant believed to be impending death").

38. Bedingfield, 14 Cox Crim. Cas. at 342-43.

39. Id. at 342 .

40. See 6 WigmoRE, supra note $11, \S 1756$ (criticizing Bedingfield as "plainly erroneous"). Interestingly, early cases often fit this pattern of a victim who named his attacker minutes after the grisly attack, just before dying of his wounds. See, e.g., Rex v. Foster, 6 Car. \& P. 325 (1834); Little Rock, M.R. \& T. Ry. Co. v. Leverett, 3 S.W. 50 (Ark. 1887). 
the event and claimed that the excitement itself insured credibility. ${ }^{41}$ Wigmore's insistence on the abandonment of any contemporaneousness requirement fashioned the current doctrine.

\section{B. The Current Doctrine}

Under the modern excited utterance exception as codified in the Federal Rules of Evidence ${ }^{42}$ (and adopted by over thirty states), ${ }^{43}$ the hearsay rule does not exclude a statement by an out-of-court declarant "relating to a startling event or condition made while the declarant was under the stress of excitement caused by the event or condition." 44 In describing the utility of this exception, modern commentators echo the historical rationale. As Weinstein and Berger explain, "The assumption underlying this exception is that a person under the sway of excitement precipitated by an external startling event will not have the reflective capacity essential for fabrication and that, consequently, any utterance will be spontaneous and trustworthy."45

Under the Federal Rules of Evidence, the excited utterance exception applies regardless of the declarant's availability to testify at trial. ${ }^{46}$ Therefore, the declarant need not testify, even if he or she is available. ${ }^{47}$

41. See 6 WIGMORE, supra note $11, \S 1747$, at 195.

42. Unlike other federal procedural rules (civil procedure, appellate procedure, criminal procedure, and bankruptcy) the federal rules of evidence are statutorily passed by Congress and not promulgated via the Rules Enabling Act. See Edward R. Becker \& Aviva Orenstein, The Federal Rules of Evidence After Sixteen Years-The Effect of "Plain Meaning" Jurisprudence, the Need for an Advisory Committee on the Rules of Evidence, and Suggestions for Selective Revision of the Rules, 60 GEO. WASH. L. REv. 857, 893-94 (1992).

43. See Gregory P. Joseph \& Stephen A. Saltzburg, The Federal Rules in the STATES iii (Supp. 1994).

44. Fed. R. Ev1D. 803(2). The Federal Rules of Evidence provide separate exceptions for spontaneous utterances distinguishing between contemporaneity and stress. Rule 803(1) preserves the present-sense impression exception for statements immediately contemporaneous with an event. See FED. R. Evid. 803(1). Rule 803(2) retains the excited utterance; it requires no precise coalescence of exclamation and event, but does require the declarant to experience and speak under the influence of the stress of the starting event. See FED. R. Evid. 803(2).

45. WEINSTEIN \& BURGER, supra note 22, I 803(2)[01].

46. Federal Rule of Evidence 803 sets forth exceptions to the hearsay rule, including the excited utterance exception, for which availability of the declarant is immaterial. See FED. R. Evid. 803. Rule 803 includes those hearsay statements that have been considered either so trustworthy as to be admissible without requiring imposition of the time and expense associated with production of a declarant if available, or of a type where cross-examination of the declarant would provide no additional information to the fact flnder.

47. An excited utterance is "not excluded by the hearsay rule, even though the declarant is available as a witness." FED. R. Ev1D. 803. Federal Rule of Evidence 804(b) sets forth exceptions to the hearsay rule for which the declarant's inabihty as a witness is required. FED. R. Evid. 804(b) (excluding from the hearsay ban statements made by a declarant who is unavailable to testify, including former testimony, statement under belief of impending death, statement against interest, etc.). For the purposes of these hearsay exceptions, unavailability of a witness is deflned in Rule 804(a). "Unavailability of a witness" includes situations in which the declarant is exempted from 
The excitement of the event, which justifies its reliability, also "serves to justify dispensing with any requirement that the declarant be unavailable because it suggests that testimony on the stand, given at a time when the powers of reflection and fabrication are operative, is no more (and perhaps less) reliable than the out-of-court statement." tity of the excited utterer need not be known, although courts and commentators advocate caution in cases involving unidentified bystanders. $^{49}$

According to many treatise writers, the contemporary excited utterance exception is "well established,"50 "time-honored," 51 and "abundantly supported by pre-Rules federal cases." 52 The Supreme Court's Sixth Amendment jurisprudence provides further indication of the entrenchment of the excited utterance exception. The Supreme Court has twice reaffirmed its faith in the excited utterance exception as historically tested and doctrinally sound..$^{53}$

testifying by ruling of the court, refuses to testify to the statement despite a court order, testifies to a lack of memory regarding the statement, or is unable to appear in court. See FED. R. EvID. 804(a).

48. MсCORMICK, supra note $7, \S 272$.

49. See, e.g., Shinner v. K-Mart Corp., 847 F. Supp. 31 (D. Del. 1994) (involving unidentified person who came to assist plaintiff who slipped on wet floor); Watson v. State, No. 94-1040, 1995 Ark. App. LEXIS (Ark. Ct. App. 1995) ("While statements made by an unidentified bystanderdeclarant may be subjected to special scrutiny, they may still fall within the excited utterance exception to the hearsay rule."); Coleman v. Spah, C5-92-713, 1992 Minn. App. LEXIS 1114 (1992) (quoting the advisory committee note "When declarant is an unidentified bystander, the cases indicate hesitancy in upholding the statement alone as sufficient [to establish the statement was made under aura of excitement]'); WEINSTEIN \& BURGer, supra note 22; CharLes AlaN WRIGHT \& Kenneth W. Graham, JR., Federal Practice and Procedure $§ 6753$, at 574-75 (1978).

50. MCCoRMICK, supra note $7, \S 272$, at 476 (conceding that "the entire basis" of the excited utterance is "subject to question" but labeling it "well established").

51. WEISSENBERGER, supra note $24, \S 803.7$, at 440 (describing the exception as "timehonored").

52. WEINSTEIN \& BURGER, supra note 22 (footnote omitted).

53. In White v. Illinois, 502 U.S. 346 (I992), the Court held that an excited utterance made to a doctor by a four-year-old girl was sufficiently reliable to overcome confrontation concerns because such an utterance was a "firmly rooted" hearsay exception. Chief Justice Rehnquist, writing for the majority, cited only Wigmore's treatise and the old case of Thompson v. Trevanion, Skinner 402 (1693), as proof that the exception was firmly rooted. See supra notes 29-32 and accompanying text. The Court concluded that hearsay that falls under the excitcd utterance "is so trustworthy that adversarial testing can be expected to add little to its reliability." White, 502 U.S. at 357.

In Idaho v. Wright, 497 U.S. 805 (1990), the Court rejected the admission of a two and a halfyear-old child's statement concerning her sexual molestation. The statement had been admitted under the residual or catch-all hearsay exception, which the Court decided was not firmly rooted but rather a newfangled crcation of the Fcderal Rules, meant to be applied sparingly and only ad hoc. See id. at 817-18. In analyzing the absence of "indicia of reliability," the Court compared the statement admitted under the residual exception to statements admittel under more fixed and respected hearsay exceptions. In dicta, the Court explained that under some exceptions, "the declarant's truthfulness is so clear from surrounding circumstances that the test of cross-examination would be of marginal utility." Id. at 820 . It cited the excited utterance as an cxample of such trustworthy hearsay. The Court explained that the "basis for the 'excited utterance' exception ... is that such statements are given under circumstances that eliminate the possibility of fabrication, coaching, or confabulation." Id. 
Nonetheless, the excited utterance exception is not as clearly established as the Supreme Court and commentators suggest. For example, in White v. Illinois, the Court recently held that an excited utterance of a four-year-old girl overcame Confrontation Clause concerns because the utterance fell within a "firmly rooted" hearsay exception..$^{54}$ The Court concluded that hearsay that qualifies as an excited utterance "is so trustworthy that adversarial testing can be expected to add little to its reliability." Yet, as proof of the "firmly rooted" nature of the excited utterance, Chief Justice Rehnquist, writing for the majority, simply cited its adoption as part of the Federal Rules and by most states. The Chief Justice listed only two sources of precedent: Wigmore's treatise and the 1693 case of Thompson $v$. Trevanion. ${ }^{56}$

The contemporary excited utterance exception also presents several recurrent doctrinal problems, including when to characterize an event as sufficiently exciting or stressful, and how to prove that the event actually occurred (in other words, whether the statement itself can prove the exciting event, or whether the proponent must adduce evidence independent of the statement). ${ }^{57}$ Most notably, courts continue to struggle with the timing question, trying to establish the maximum time that may elapse between the event and the statement for the declaration to fall within the exception. ${ }^{58}$ According to the Advisory Committee note, "the standard of measurement is the duration of the state of excitement." 59 This is clearly a fact-bound inquiry; in fact, courts look for indications of continuing excitement based on many diverse factors, such as the nature of the startling event and the age and temperament of

54. 502 U.S. $346,356-57$ (1992). The Court in White purportedly adhered to the standard it articulated in Ohio v. Roberts, 448 U.S. 56 (1980), which it interpreted as holding that use of "firmly rooted" hearsay exceptions do not violate an accused's right to confrontation under the Sixth Amendment. See also Wright, 497 U.S. at 805.

55. White, 502 U.S. at 357 (citing Wright, 497 U.S. at 820-21). Criticism of the Court's Sixth Amendment jurisprudence is widespread. Professor Eleanor Swift has aptly described the Court's opinion in White as "overbroad, unjustified and embarrassing." Eleanor Swift, Smoke and Mirrors: The Failure of the Supreme Court's Accuracy Rationale in White v. Ilinois Requires a New Look at Confrontation, 22 CAP. U. L. REv. 145, 152 (1993). For the purposes of this inquiry, however, it is interesting to observe the Court's confidence in the excited utterance exception.

56. See White, 502 U.S. at 355 n.8. This is particularly troubling given the prospect that Thompson v. Trevanion, Skinner 402 (1693), is subject to alternate interpretations, and that Wigmore shaped the doctrine much more than merely restating it. See supra note 32 .

57. See, e.g., FED. R. EvID. 803(2) advisory committee's note (commenting on question of proving the startling event); WeINSTEIN's EvidENCE, supra note 22, II 803(2)[01].

58. See MCCoRMICK, supra note $7, \S 272$ (casting the temporal element as probably the most important of the many factors entering into the determination); see also Haggins v. Warden, 715 F.2d $1050,1057-58$ (6th Cir. 1983) (weighing whether a child's statement made an hour and a half after the event should be excluded).

59. FED. R. Evid. 803(2) advisory committee's note. The advisory committee questions, "How long can excitement prevail? Obviously there are no pat answers and the character of the transaction or event will largely determine the significance of the time factor." Id. (citing M.C. Slough, Spontaneous Statements and State of Mind, 46 IowA L. REv. 224, 243 (I961)). 
the declarant.$^{60}$ However, such a fact-bound inquiry produces widely varying and unpredictable results. In some cases, a lapse of an hour is too long, while in other, albeit rare, cases, twenty hours of continuous agitation meets the excited utterance standard. ${ }^{61}$

Moreover, despite codification of the evidence rule, trial judges still possess enormous discretion in deciding whether to admit these statements. Where sympathy exists for the victim, particularly in child abuse cases, courts often stretch the excited utterance doctrine beyond recognition-both in imputing stress ${ }^{62}$ and in extending the time that the declarant is under the influence of that stress well beyond traditional limits. ${ }^{63}$

The willingness of some courts to stretch the doctrinal requirements, though understandable and sometimes even admirable, causes

60. See, e.g., People v. Soto, 35 Cal. Rptr. 2d 846, 860 (Ct. App. 1994) (describing victim, who made an excited utterance within four hours of the attack, as "either crying, wringing her hands, covering her face, averting her eyes from whomever was talking to her or talking about how scared, upset and nervous she was"); People v. Brown, 517 N.E.2d 515, 519 (N.Y. 1987) (citing specific factors such as the victim's "hemorrhagic shock" and resuscitation in addition to lack of time to reflect in the thirty minutes between the shooting and the victim's einergency room statement as indications of spontaneity).

61. Compare Pacifico v. State, 642 So. 2d 1178, 1187 (Fla. Dist. Ct. App. 1994) (excluding statement made only approximately one hour after a violent rape as an excited utterance because "the time lapse between the sexual encounter and the victim's statements to her roommates was sufficient to permit reflective thought") and Handel v. New York Rapid Transit Corp., 297 N.Y.S. 216 (App. Div. 1937), affd mem., 13 N.E.2d 468 (N.Y. 1938) (excluding statement made two and one-half minutes after declarant had been dragged by a train) with State v. Stipek, 995 Ohio App. LEXIS 1355, at *3 (Ohio C. App. 1995) (holding that the "precise amount of time that may lapse before a statement loses its spontaneity as an excited utterance eannot be established by any absolute rule of law" and finding no abuse of discretion where statements to survivor's boyfriend made four to six weeks after the alleged offense were allowed as excited utterances) and People v. Houghteling, 455 N.W.2d 440 (Mich. Ct. App. 1990) (admitting statement of five-year-old made 20 hours after assault).

62. See Robert P. Mosteller, Remaking Confrontation Clause and Hearsay Doctrine Under the Challenge of Child Sexual Abuse Prosecutions, 1993 U. ILL. L. Rev. 691, 706 n.68 (1993). Courts also tend to credit children's statements about sexual assault because they do not believe children have sufficient knowledge or sophistication to fabricate sexual encounters. See, e.g., State v. Logue, 372 N.W.2d 151, 159 (S.D. 1985) (holding that statements made by four-year-old boy to his mother in normal course of daily activities two to three days after the traumatic event, "coupled with the inability we perceive of the child to fabricate an account of such a heinous sexual encounter, warrant a finding that the statements were excited utterances").

63. See Mosteller, supra note 62 (explaining expansion of allowable time period bctween the exciting event and hearsay statement "under a theory that the psychological characteristics of children either cause excitement to inhibit reflective thought for a longer period of time or greatly minimize that danger [of fabrication]"); see also McCoRMICK, supra note 7, § 272.1, at 478 ("many courts have liberally interpreted the allowable period of time between the exciting event and the child's description of it"). See, e.g., Guam v. Ignacio, 10 F.3d 608, 615 (9th Cir. 1993) (holding that the time factor may be lengthened in cases of molestation by adult male family members because it is particularly traumatic); Morgan v. Foretich, 846 F.2d 941, 947-48 (4th Cir. 1988) ("tendcr years" reduce likelihood of "reflection and fabrication"); State v. Smith, 337 S.E.2d 833, 842-43 (N.C. 1985) (holding that time lapse of two to three days still resulted in admissible utterance). See generally Harrington, supra note 28 (dividing excited utterances by time and distinguishing minors from adults). 
confusion and inconsistency. ${ }^{64}$ Although such resort to legal fiction may seem compassionate in individual cases, the legal standard has become undesirably muddled. As a result, the excited utterance exception sometimes operates as the unofficial garbage pail of hearsay exceptions. ${ }^{65}$ It occasionally functions as a de facto residual exception without the doctrinal limitations of the narrowly-drawn residual hearsay exception currently codified under the rules. ${ }^{66}$

Furthermore, the problem is not as simple as judges ignoring the formal requirements of a silly rule to achieve a fair result. Judicial stretching of the excited utterance exception is by nature selective and motivated by a distinct point of view. While some judges seem reluctant to allow legal formalism to triumph, others adhere to the doctrine rigidly. ${ }^{67}$ Such literal and unbending applications of the excited utterance doctrine, particularly with respect to issues of timing, arise even in sympathetic cases. Therefore, the excited utterance exception is applied in a chaotic and idiosyncratic manner; this inconsistency bespeaks unfairness and unequal treatment of similar out-of-court statements.

These inconsistent responses by judges reveals basic flaws in the doctrine and, perhaps, in the hearsay rule itself. Moreover, as the next Section shows, there is reason to doubt that the excited utterance exception's reliance on timing and stress guarantees trustworthiness.

64. Cf. Lauren Robel, Fractured Procedure: The Civil Justice Reform Act of 1990, 46 STAN. L REv. 1447 (1994) (explaining the importance of uniformity and predictability in procedural rules).

65. See State v. Parker, 730 P.2d 921, 924 (1daho 1986) ("In sex crime cases, the excited utterance exception often receives broader application than in other cases."); John E. B. Myers, The Child Sexual Abuse Literature: A Call for Greater Objectivity, 88 Mich. L Rev. 1709, 1729-30 (1990) (book review) (noting the "particularly troublesome" expansive use of the excited utterance in child abuse cases).

66. Federal Rule of Evidence 803(24) provides residual, or catch-all, exceptions to the hearsay rule. Rule 803 (24) excepts from the hearsay rule "a statement not specifically covered by any of the foregoing exceptions but having equivalent circumstantial guarantees of trustworthiness...." FED. R. EvID. 803(24). The court may admit the statement upon a finding that the statement is offered as evidence of a material fact, that it is more probative on the point for which it is offered than any other evidence which the proponent can procure through reasonable efforts, and that the general purposes of the Rules and interests of justice will be best served by the admission of the statement. See id. The proponent of the statement must give notice to the adverse party in advance. See id. Ruhings made under the residual exception have no precedential effect. See WEINSTEIN \& BURGER, supra note 22, II 803(24)[01] (noting that catchall decisions have only limited precedential effect); Thomas $M$. Mengler, The Theory of Discretion in the Federal Rules of Evidence, 74 lowA L. REv. 413, 452 (1989) ("Because a proper determination under the catchall exception is largely dependent on the peculiarities of the particular trial, trial court rulings under the catchall exception and appellate affirmances or reversals legitimately carry no precedential value.").

67. See, e.g., State v. Thomas, 777 P.2d 445, 449 (Utah 1989) ("While it is true that the victim was still under the stress and shock of the assault, we believe that we would be pushing the limits of the rule to hold admissible the entire contents of this one-hour interview as an 'excited utterance."'); People v. Brown, 524 N.E.2d 742, 747-78 (11l. App. Ct. 1988) (holding that 50 minutes from event to statement, and victim's reflection on whether she should call the police 10-15 minutes before her statement was made, constituted "pause to reflect [that] negated the spontaneity of her statement"). 


\section{The Psychological Critique of the Excited Utterance Doctrine}

The excited utterance exception has been subjected to extensive psychological criticism. While this Article does not comprehensively examine this critique of the doctrine, it does outline it. Perhaps what is most remarkable is not the critique itself but the continued resilience of the excited utterance doctrine in the face of this persuasive psychological critique. This persistence despite decades of criticism demonstrates the entrenchment of the doctrine and prompts inquiry regarding the special hold that the excited utterance doctrine has on our jurisprudence and culture.

Today, Wigmore's description of the effect of stress seems primitive and one-sided. His analysis of the effect of stress-that it stills conscious thought-undervalues other factors in the complicated process of perception. From a functional as well as a philosophical point of view, Wigmore's theory underestimates the vast cognitive processes that transpire as part of any utterance. Even as a declarant spontaneously yells, "MY GOD, the car ran the red light!" he is thinking, making choices, processing images, translating those images, and choosing words. It is, therefore, hard to divine what part of that complicated process is deliberate and what part is "instinctive" or "impulsive."

Furthermore, despite its intuitive appeal, Wigmore's notion that a person would not have time to think up a lie before making an excited utterance in response to a startling event is not borne out by psychological research. The time required to craft a lie is slight-sometimes only a matter of seconds. ${ }^{69}$ The excited utterance exception, which tolerates more than a thirty-minute gap between the event and the utterance, allows more than sufficient time for planning a false report.

68. See Stanley A. Goldman, Distorted Vision: Spontaneous Exclamations as a "Firmly Rooted" Exception to the Hearsay Rule, 23 LoY. L.A. L. REv. 453, 459 (1990) (questioning the "assumption that descriptive accuracy is a natural consequence of immediate observation"); Stewart, supra note 16 at 29 ("[E]ven without considering falsification and the distorting effect of excitement, contemporaneous utterances are subject to distortion in the declarant's perception and memory (the declaration need only be substantially contemporaneous) as well as the perception and memory of the reporting witness.").

69. See Robert M. Hutchins \& Donald Slesinger, Some Observations on the Law of Evidence, 28 CoLum. L. REv. 432,437 (1928) (asserting that the difference in reaction time between deceptive and sincere responses is negligible). Psychological studies support this observation and indicate that the difference between the time of cognition and the time when the declarant may begin to fabricate is so small that it is often impossible to measure without instruments. See Goldman, supra note 68, at 460 (arguing that "the hearsay statement would have to be spoken virtually simultaneously with the described event for even the slightest assurance of increased reliability"); Quick, supra note 22, at 210 (noting psychological studies questioning the argument that spontaneity is a reasonable guarantce of sincerity); Stewart supra note 16, at $28 \mathrm{n} .126$ (citing HAROLD ERNEST BURTT, LEGAL PSYCHOLOGY (1931)). 
Finally, and most importantly, the excited utterance doctrine's emphasis on sincerity obfuscates the much more pressing issues of perception and memory. ${ }^{70}$ It reflects the disproportionate concern that evidence law evinces for deliberate falsification, as compared with honest error produced by the normal operation of cognitive processes. ${ }^{71}$ Psychological reordering and confabulation permeate all human observation; they do not necessarily arise out of a desire to lie, but merely reflect the complex process of human perception. The psychological literature indicates that perceiving and remembering are more decisively matters of construction than mechanical recording and reproduction. ${ }^{72}$ If twentieth-century intellectual thought has taught us anything, it is how intricate human thought and awareness are, and yet how generally oblivious we are to their processes.

70. As my colleagues Professors Jeffrey Rachlinsky and Alex Tanford have explained to me, a person experiences a series of cognitive stages in translating a live event into a witness' testimony: sensation (the activation of neural receptors in response to stimuli); perception (the automatic process of assembling sensations into a mental representation of the world); encoding (moving the perception into memory); storage (keeping the memory intact); and retrieval (retrieving the event from longterm memory). See Charles G. Morris, Psychology: AN Introduction 232-238 (9th ed. 1996) (discussing sensation, perception, encoding, and retrieval). Breakdown at any one of these stages will result in an inaccurate or incomplete memory. For instance, if observers do not have enough time to process and encode the event, they may engage in perceptual confabulation, whereby their overloaded brains unconsciously attempt to fill in the gaps in information. See ClifFord \& BulL, The Psychology of Person Identification 17-18 (1978).

There are at least three types of memory: (1) sensory memory, lasting less than one second (just long enough to store sensory information), see The ENCYClOPEDic DictionaRy of Psychology 207 (Terry F. Pettijohn editorial adviser, 4th ed. 1991); (2) short-term memory, defined as "the working memory that contains information currently in use being acted upon and in consciousness"; and (3) long-term memory, which corresponds to "everything we "know." MoRRIs, supra at 234. Excited utterance concerns long-term memory-even if the utterance was made only five minutes after the startling event. Memory of five minutes ago is linked to long-term memory rather than short-term memory because short-term memory is not measured merely by time elapsed between an event and recalling that event. Rather, it is measured in terms of the capacity to hold a certain amount of information in the working consciousness. Once information has left consciousness, or short-term memory, it is stored as long-term memory, or lost in 15 to 20 seconds. See CharLes G. MoRris, Psychology: AN INTROduction 226-29, 234 (7th ed. 1990); YARMEY, The Psychology OF EYEWITNESS TESTIMONY 57-62 (1979) (charting various types of memory and listing short-term as that which can be retained for $15-20$ seconds).

71. This highlights a fundamental question underlying the hearsay doctrine: Why is sincerity the emphasis of so many exceptions to the hearsay rule? Of the four hearsay dangers (perception, memory, narration, and sincerity) why does solving the problem of sincerity seem to assuage the other three concerns about reliability? Honest people can be wrong. There is a wealth of literature on the unreliability of eyewitness testimony. See D.S. Greer, Anything But the Truth? The Reliability of Testimony in Criminal Trials, 11 BRIT. J. CRIMINologY 131, 133-35 (1971), quoted in Steven 1. Friedland, On Common Sense and the Evaluation of Witness Credibility, 40 CASE W. RES. L. REv. $165,167 \mathrm{n} .14$ (1990) (discussing inaccuracy of juries in evaluating eyewitness testimony). One explanation for the emphasis on sincerity stems from Professor lmwinkelried's hypothesis of the "worst evidence principle." Our fear of lying witnesses surpasses, and perhaps overwhelms, any other reliability concerns. See Imwinkelried, supra note 10.

72. See Stewart, supra note 16, at 10 (quoting F. Bartlett, Remembering 204, 205 (paperback ed. 1967)). 
For decades, scholars have attacked the wisdom of fashioning an exception to the hearsay rule that depends upon the excited and stressful state of the speaker. ${ }^{73}$ Although the psychological evidence is mixed, the standard psychological critique questions the reliability of excited utterances. ${ }^{74}$ Whereas the excited utterance exception is premised on the notion that stress leads to sincerity, many scholars instead propose that extreme stress leads to confusion. ${ }^{75}$ Even assuming that the declarant's sincerity is enhanced by his or her agitated state, the reliability of the excited utterance may in fact be counterbalanced, or even outweighed, by the declarant's diminished perception and memory. ${ }^{76}$ Declarants' startled utterances may be honest declarations of what they

73. In fact, the first criticisms of the excited utterance exception are almost as old as Wigmore's formulation of the doctrine itself. In a famous 1928 article, entitled Some Observations on the Law of Evidence, Professors Hutchins and Slesinger raised practical and psychological concerns about courts' treatment of spontaneous declarations. See Hutchins \& Slesinger, supra note 69. They noted that courts tended to favor excited utterances over present sense impressions, and that courts felt most comfortable admitting evidence where the declarant was under the stress of an exciting event. See id. at 433 . They argued that the reverse should be true, and that present sense impressions, uttered precisely while the event transpired, were more reliable. See id. at 440 . The excited utterance exception, because it allows a brief time lag between the event and the exclamation and depends on excitement to ensure sincerity, was, in the estimation of Hutchins and Slesinger, less reliable, although still admissible. See id:; see also David P. Leonard, Perspective on Proposed Federal Rules of Evidence 413-415: The Federal Rules of Evidence and the Political Process, 22 FORDHAM URB. LJ. 305, 315 (1995) (discussing the questionable psychology of the excited utterance); Moorehead, supra note 22, at 203 (criticizing the excited utterance and asking "[w]ould you entrust your life to the judgment or perception of a person who is acting under extreme stress or trauma?").

74. See James Marshall, Law and Psychology in Conflict 16 (1966) (criticizing the excited utterance because it ignores "the distorting impact of trauma on the capacity to perceive"); McCoRmick, supra note $7, \S 272$, at 476 ("The entire basis for the exception is, of course, subject to question. While psychologists would probably concede that excitement minimizes the possibility of reflective self-interest influencing the declarant's statements, they have qucstioned whether this might be outweighed by the distorting effect of shock and exeitement upon the declarant's observation and judgement."); Kenneth A. Deffenbacher, The Influence of Arousal on Reliability of Testimony, in Evaluating Witness Evidence 235, 236 (Sally M.A. Lloyd-Bostock \& Brian R. Clifford eds., 1983) (criticizing the apparent view of American courts that heightened arousal increases accuraey of memory).

75. Stress is defined as "environmental challenges severe enough to threaten psychological or physiological well-being." Peter D. Spear et al., Psychology: Perspectives on Behavior 545 (1988). The terms stress, excitement, and arousal are used interchangeably. See Deffenbacher, supra note 74 (using "stress," "arousal," and "excitement" interchangeably). Stress can infect the complicated process of imprinting, absorbing, and receiving information. See id. at 247-48 (noting lack of empirical support for idea that high levels of arousal facilitate eyewitness testimony, and noting that violence may further impair witness testimony). The "startling event" of the excited utterance rule, whieh typically includes accidents and violent crimes, elearly falls within the psychological definition of stress, even if the declarant is only a bystander as opposed to a participant or a victim.

76. Or as Hutchins and Slesinger concluded, "What the emotion gains by way of overcoming the desire to lie, it loses by impairing the declarant's power of observation." Hutchins \& Schlesinger, supra note 69 , at 439. 
thought they saw, but the very stress that makes them so honest can also interfere with their ability to perceive, transcribe, and remember events. ${ }^{7}$

One prominent psychological theory of stress and memory posits that the level of fear or stress experienced in acquiring information influences the quality of information stored in long-term memory. ${ }^{78} \mathrm{Be}$ sides the distracting excitement itself, there may be strong personal feelings evoked by the startling event that affect memory and perception. ${ }^{79}$ These factors conspire to undermine the accuracy of the excited statement and, in turn, raise serious questions about the theory of the excited utterance exception.

77. In 1937, Professor Morgan similarly criticized the trend toward requiring a startling occurrence for res gestae. The requirement "seems a decided mistake, for it insists upon an element which has a positive tendency to produce inaccurate observation-and inaccuracy of observation is one of the greatest obstacles to the discovery of facts in litigation." Edmund M. Morgan, Res Gestae, 12 WASH. L. REV. 91,98 (1937).

78. See Elizabeth F. Loftus \& James M. Doyle, Eyewitness Testimony: Civil and Criminal 47-51 (1987). The complex role of stress in perception and the efficiency of memory has been encapsulated in the Yerkes-Dodson law. See id. at 48. The Yerkes-Dodson law posits the existence of an optimal stress level in which the observer performs at his perceptual peak. Too little stress, and the observer's nervous system may not function fully. See id. Without any arousal or anxiety the observer may pay insufficient attention. Too much stress, however, impairs perception and memory, creating a "disorganizing effect." The Yerkes-Dodson curve plots the level of arousal against the efficiency of memory as measured by task performance. See Deffenbacher, supra note 75, at 237. For tasks of any real complexity, the relationship between arousal and performance is curvilinear. The optimal stress level varies with the nature of the activity. The more excited a person is, the less complexity he can handle. See id. Excited utterances concern higher than optimal stress levels. See id. at 247 ("[A]rousal levels engendered by crimes of violence, homicides, rapes, assaults, armed robberies, are almost invariably going to be greater than the Yerkes-Dodson optimum, given the reasonable high complexity of the task expected of eyewitnesses."). Clifford and Bull observed that "[u]nder conditions of stress, anxiety and fear the level of cognitive complexity used to perceive with may be very sub-optimal." Clifford \& BulL, supra note 70, at 51. Perhaps the closest simulation of the condition of excited utterance stems from staged exciting events or violent films, after which the observer's perception and memory are tested. Clifford and Hollin conducted an experiment where subjects viewed films with varying levels of violence. The subjects' arousal was measured by galvanic skin responses. Photographic identification was less accurate for subjects viewing the more violent film, and such subjects' lower recall of the perpetrators' personal characteristics was statistically significant. See Deffenbacher, supra note 75, at 244 (citing B.R. Clifford \& C.R. Hollin, Effects of the Type of Incident and Number of Perpetrators on Eyewitness Memory, 66 J. APPLIEd Psychol. 364-70 (1981)). Loftus and Burns showed witnesses either a violent or a non-violent version of a bank robbery. The observers shown the violent film where a young boy is shot in the face recalled and recognized less detail from the film. See id. at 245 (citing E.F. Loftus \& T.E. Burns, Mental Shock Can Produce Retrograde Amnesia (198I) (paper presented at meetings of the Psychonomic Society, Philadelphia)). In addition, the experimenters showed that the memory impairment derived from the shock of the violent episode rather than merely the surprise of the hold-up. See id. Finally, in a simulated robbery which transpired in a classroom of over one hundred unsuspecting college students, researchers found that students who reported less stress during the incident were significantly more accurate in identifying the thief. Clifford \& BuLL, supra note 70, at 53-54.

79. Loftus and Doyle cite evidence that people who experience natural disasters, such as floods or earthquakes, often remember very little, particularly when the memories are painful. See id. at 32. Another study indicates that the more violent and emotion-provoking the crime, the less well it will be remembered. See id. at 51 . 
Additionally, some psychological data indicate that, as a selfprotective device, witnesses may initially suppress unpleasant memories, which only emerge in later, calmer times. ${ }^{80}$ Such data argue directly against application of the excited utterance exception, because the witness' ability to recall will not be at its best so near in time to the traumatic event.

The picture that emerges from the recent psychological literature on the effect of stress on memory, however, is neither simple nor particularly coherent. Some of the early works on stress and accuracy may be criticized because they fail to consider the connection between the stressful event and the particular facts to be remembered. Similarly, they do not account for the type of information to be remembered. ${ }^{81}$ Moreover, some modern psychologists dispute the notion that stress always diminishes accurate observation, and argue instead that arousal may improve accurate memory of certain central information..$^{22}$ These psychologists assert that an excited event can occupy all of a person's working short-term memory. As a result, the person becomes focused on the event and cannot think about anything else. This circumstance thus impedes the person's ability to fabricate. ${ }^{83}$

Fortunately, this Article need not stake out a position on this debate within psychology because the excited utterance exception, as currently applied, makes no sense under either theory. Even assuming that stress has a positive, focusing effect, that effect is short lived, because it applies to short-term memory. The excited utterance exception, however, routinely admits statements made thirty minutes after the exciting event. This gap in time is too long to obtain the benefit from this postulated window of sincerity.

For the purposes of this Article, the more important conclusion is that the excited utterance doctrine remains vibrant despite serious psychological criticisms of its efficacy and wisdom. Whatever the merits of the traditional psychological critique, it is fascinating and telling that a powerful and longstanding critique of the excited utterance doctrine exists, and yet the doctrine has remained widely accepted and applied,

80. See Sven-Ake Christianson, Emotional Stress and Eyewitness Memory: A Critical Review, 112 Psychol. Bull. 284, 290-94 (1992) (noting the central features of unpleasant events may be better remembered than neutral events, but such enhanced memory will occur after a lapse of time).

81. Additionally, some of these early experiments did not adequately account for the many variables that may affect the experimental outcomes, including the nature of the stressful event, the level and duration of stress actually experienced, and the variations in individual stress tolerance. $1 \mathrm{n}$ fact, a persistent problem with the psychological research stems from the ethical limitations on scientists in inducing stress levels equivalent to those caused by violent crimes or car accidents.

82. See Howard Egeth, Emotion and the Eyewitness, in THE HEART'S EYE: EMOTIONAL 1NFLUences 1N PERception and AtTEntion 257-58 (P.M. Neidenthal \& S. Kitayama eds., 1994).

83. See id. 
and even venerated. ${ }^{84} \mathrm{~A}$ feminist analysis, examining how the excited utterance exception represents and perhaps even influences cultural values, may explain the tenacity of the doctrine in the face of such scholarly criticism. ${ }^{85}$

III

\section{A Feminist Perspective}

\section{A. Difference, Dominance, and Evidentiary Objectivity}

Modern feminism, which grew out of a conscious attempt to respect women's voices and experiences, has developed analytical tools to examine how those voices are heard and how those experiences are processed. ${ }^{86}$ Professor Deborah Rhode has explained that a feminist method "implies a commitment to gender as a focus of concern and to analytic approaches that reflect women's concrete experience." ${ }^{87}$ Feminist method examines the status quo to "identify the gender implications of rules and practices which might otherwise appear to be neutral or objective." It screens for rules and cultural norms that conflict with the experience of women, drawing insight from women's psychological experience of being "other" $\mathrm{r}$ " and from women's practical experience

84. See supra notes 50-52 and accompanying text (describing the Supreme Court's recent support for the doctrine).

85. Of course, another explanation for the excited utterance doctrine's longevity may be that jurists generally disregard the advice of evidence scholars and psychologists. Here, for obvious reasons, I eschew Occam's razor, which prefers the simplest of all competing theories. See A. Samuel Oddi, Un-Unified Economic Theories of Patents-The Not-Quite-Holy-Grail, 71 NoTRE DAME L. REv. 267, 285 n.128 (1996).

86. Some argue that modern feminism arose from consciousness-raising groups and attempts to speak out against gender inequalities. See Leslie Bender, A Lawyer's Primer on Feminist Theory and Tort, 38 J. LEGAL Educ. 3, 9 (1988) (describing consciousness-raising as the process of validating women's experience and learning from these experiences). Although feminists disagree about how to interpret women's experiences and what to do about them, all feminists are dedicated to the fundamental goal of eliminating the oppression of women. See Lynne Henderson, Law's Patriarchy, 25 L. \& Soc'Y REV. 411, 417 (1991) (noting the shared goal of all branches of feminism to eradicate women's subordinate status).

87. Deborah L. Rhode, The "No Problem" Problem: Feminist Challenges and Cultural Change, 100 YALE LJ. 1731, 1736 (1991); see Patricia A. Cain, Feminist Jurisprudence: Grounding the Theories, 4 Berkeley Women's L.J. I9I, 195 (1989-90) ("[T]here does appear to be general agreement that feminist method begins with the primacy of women's experience.").

88. Katharine T. Bartlett, Feminist Legal Methods, reprinted in FEMINIST LEGAL ThEORY: Readings in LAW aNd Gender 370, 371 (Katharine T. Bartlett \& Rosanne Kennedy eds., 1991) (describing this as "the woman question"). Bartlett presents a method for feminist analysis that is designed to "reveal features of a legal issue which more traditional methods tend to overlook or suppress." Id. at 371-74.

89. See id. at $\mathbf{3 8 5}$ (discussing "feminist standpoint epistemology," which "identifies woman's status as that of victim, and then privileges that status by claiming that it gives access to understanding about oppression that others cannot have"). 
of unequal treatment. .0 In domg so, feminist method sheds light on cultural biases, exposes power differences between the sexes, and challenges the cultural, social, and legal status quo.

In applying a feminist method to evidence law, this Article draws on two important schools of feminism: "difference feminism," also known as relational or cultural feminism, and "dominance," or radical, feminism. I have chosen these two schools of thought because they are the most prominent and current, and because they are rich in theory. Drawing on political, philosophical, and socio-linguistic contributions to understanding gender in our society, difference and dominance feminism offer excellent tools for analyzing evidence law.

Difference feminism posits that women, as a result of their socialized roles, or perhaps (more controversially) their natural propensities, perceive and think about the world differently from the way that men do. Strongly influenced by the "ethic of care" articulated by Nel Noddings and Carol Gilligan, ${ }^{92}$ difference feminists argue that women have unique ways of knowing and relating that differ from men's approaches. Without claiming that this different voice is descriptive of all women, ${ }^{93}$ or necessarily better than the approach used by men (although this is sometimes implied), these feminists have attempted to identify the nature of a "different voice." Difference feminists contend that whereas men's interactions are often governed by hierarchy and status,

90. See generally Robin L. West, The Difference in Women's Hedonic Lives: A Phenomenological Critique of Feminist Legal Theory, 3 W1s. WoMEN's L.J. 81 (1987) (arguing that women experience pain differently from men, and that feminist method should describe women's subjective lives, especially their differing painful experiences). For soine concrete observations about how law and legal language prefer a male perspective, see Lucinda M. Finley, Breaking Women's Silence in Law: The Dilemma of the Gendered Nature of Legal Reasoning, 64 NotrE DAME L. REv. 886, 898 \& nn. 56-61 (1989).

91. Even among difference feminists, there are serious differences. Some difference feminists seem to argue that women's differences from men derive from the essential nature of women themselves, emanating, if not from biology, then from biologically driven roles stemming from women's potential for childbirth and nursing. See, e.g., Robin West, Jurisprudence and Gender, 55 U. CHI. L. REv. 1, 14 (1988) ("Underlying both radical and cultural feminism is a conccption of women's existential state that is grounded in women's potential for physical, material connection to human life.") Others emphasize emotional and social experiences of young girls from a psychoanalytic perspective and attribute women's connectedness to the fact that, unlike boys, girls do not have to reject their mothers. See, e.g., NANCY Chodorow, THE REProduction of Mothering 167 (1978) (exploring the different effects of the Oedipus complex on boys and girls).

92. See generally Nel Noddings, Caring: A feminine Approach to Ethics \& Moral Education (1984); Carol Gilligan, In a Different Voice (1982).

93. Difference feminists have been accused of ignoring differences among women. For instance, women of color have felt that the feminist movement represents only white, middle-class women, "the pampered oppressed" (to use a phrase of Alice Walker's) who do not have to deal with the complicating factors of race and poverty. Some lesbians feel ignored and alienated by difference feminists' emphasis on childbirth and nursing in describing women's unique experience and connectedness. See generally Elizabeth V. Spelman, Inessential Woman: Problems of Exclusion IN Feminist Thought (1988); Cain, supra note 87; Angcla P. Harris, Race and Essentialism in Feminist Legal Theory, 42 Stan. L. Rev. 581 (1990). 
women tend to rely on "webs of interconnectedness." Difference feminists identify the masculine voice as one that settles disputes through organized conflict such as war or litigation..$^{95}$ The feminine voice, on the other hand, approaches problems through consensus building. ${ }^{96}$ In light of women's focus on relationships, the feminine voice tends to eschew abstract rights-based arguments ${ }^{97}$ and instead prefers to immerse itself in the particulars of problems, seeking contextbased solutions. ${ }^{98}$ Difference feminists affirmatively recognize and even celebrate these unique ways of thinking, knowing, and relating.

94. GilligaN, supra note 92, at 24-36, quoted and discussed in Bender, supra note 86 , at 2830. Almost all feminists agree that personal relationships and connections with other people form an important aspect of women's experience. See Robin West, Jurisprudence and Gender, 55 U. CHI. L. REv. I, 14 (1988) ("Underlying both radical and cultural feminism is a conception of women's existential state that is grounded in women's potential for physical, material connection to human life ....").

95. As Professor Carrie Menkel-Meadow notes in Portia in a Different Voice: Speculations on a Women's Lawyering Process, 1 Berkeley Women's L.J. 39, 50-51 (1985) [hereinafter MenkelMeadow, Portia in a Different Voice], the adversary system relies on a strict hierarchy and a clash of rights, ultimately dividing the parties into categories of winners and losers. Professor Leslie Bender contends that the adversary system is "[i]n many ways . . . an intellectualized substitute for duelling or medieval jousting. Much of legal practice is a win-lose performance, full of one-upmanship and bravado." Bender, supra note 2, at 7 . The culture of the adversary system and the evidence rules themselves promote a gaming atmosphere. See Kinports, supra note 2, at 426-27. The language of advocacy is gendered and bellicose, full of sports and war analogies and "masculine" imagery. See, e.g., Emily Couric, The Trial Lawyers: The Nation's Top Litigators Tell how They WiN ix (1988) (referring to trial lawyers as "the shock troops of the legal profession").

Some feminists have rejected the notion that litigation and adversariness is per se male and bave examined feminist principles for litigation. For example, Menkel-Meadow lias revisited her position in the Portia articles in a piece entitled Portia Redux: Another Look at Gender, Feminism and Legal Ethics, 2 VA. J. Soc. PoL'y \& L. 75, 86-97 (1994) [hereinafter Menkel-Meadow, Portia Redux], in which slie claims that although women may first turn to negotiation and consensus, they also have the skills of the adversary system, including slarp lawyering and technical interpretations.

96. See Deborah TANnen, You Just Don't Understand 149-87 (1990) (discussing women's tendency to avoid direct conflict and to try to maintain consensus and cohesion within a group); see also Menkel-Meadow, Portia in a Different Voice, supra note 95, at 40 (summarizing psychological and sociological research that "has postulated that women grow up in the world with a more relational and affiliational concept of self than do men").

97. Professor Katharine Bartlett addresses the general claim "that women approach the reasoning process differently than men do." According to Bartlett, the argument runs that women are "more sensitive to situation and context, that they resist universal principles and generalizations, especially those that do not fit their own experiences, and that they believe that 'tle practicalities of everyday life' should not be neglected for the sake of abstract justice." Bartlett, supra note 88, at 377. Professor Bartlett is clearly skeptical of these claims. She notes that "this reasoning process has taken on normative significance for feminists." Id. Bartlett rightly points out that feminist method requires the process of abstraction. See id. at 380 . It is not the process of abstraction but rather the absence of practical reasoning, and the failure to integrate emotion and experience with logic that the feminist method tries to redress. See id.

98. See TANNEN, supra note 96, at 91 (discussing "women's tendency to use personal experience and examples, rather than abstract argumentation"); Mari J. Matsuda, Liberal Jurisprudence and Abstracted Visions of Human Nature: A Feminist Critique of Rawl' Theory of Justice, 16 N.M. L. REV. 613, 620 (1986) (noting that "[t]ime and again woinen have found that their own experiences are more valuable truth-seeking tools than the abstractions of others"); Menkel- 
Difference feminism has been assailed on many fronts, including challenges by liberals who insist on precise parity ${ }^{99}$ and by those who bristle at the notion that women have somehow cornered the market on caring, contextualized judgment. ${ }^{100}$ Difference feminism, however, rejects "equality" as a sterile and ultimately unfair precept, because it does not account for women's experiences and mindset. ${ }^{101}$ Moreover, in response to the criticism that difference feminists have arrogated to themselves all the desirable, "cuddly" qualities, it is important to note that difference feminism, though not the exclusive proponent of the values inherent in the ethic of care, has nevertheless been the primary force in bringing such values to bear on legal doctrine and legal culture. This contribution of feminism and feminist scholarship is significant

Meadow, Portia in a Different Voice, supra note 95, at 48 (discussing the works of Carol Gilligan and Nel Noddings, and observing that "[m]en focus on univcrsal abstract principles like justice, equality and faimess so that their world is safe, predictable and constant. Women solve problems by sceking to understand the context and relationships involved and understand that universal rules may be impossible."); Menkel-Meadow, Portia Redux, supra note 95, at 80 (reviewing the more recent data and asserting that "most men, and about one-third of women, reason from rational, abstract principles or rules, like a weighing of compcting rights. Women are more likely, though not exclusively, to reason from a care perspective that relies on notions of responsibility, human connection, and care.") (footnote omitted). See generally MARY Field BELENKY ET AL., WOMEN's WAYS of KNOWing: The Development of Self, Voice, and Mind (1986) (discussing women's methods of gaining knowledge and information).

99. Such criticism comes from people who are skeptical of the existence of different voices and who are wary of citing differences, even if they do exist. They believe that the women's movement should focus on attaining equality of treatment and opportunity. See, e.g., Frances Olsen, The Sex of Law, in The Politics of LAw 453, 458 (David Kairys cd., 1990) (noting that the rejection of the "sexualization of the dualisms" of rational and irrational, active and passive, etc., "is often accompanied by ... a disruption of conventional sex roles"). Feminists who focus on equality are concerned with losing ground on issues of cqual pay and glass ceilings if women are branded as "different," even if that difference is not necessarily perceived by fcminists as bad. The fear is that difference feminism, which emphasizes values of nurturing and empathy, may inadvertently polarize the sexes and reinforce beliefs that are used to justify the oppression of women. See, e.g., Anne M. Coughlin, Excusing Women, 82 CALIF. L. REv. 1, 90-91 (1994) (arguing that the ethic of care obscures "feminist efforts to clarify our understanding of gender as a patriarchially constructcd hierarchy of social differences and behavioral expectations"); Joan C. Williams, Deconstructing Gender, 87 MrCH. L. Rev. 797 (1989) (arguing that Gilligan's construction of gcnder reinforccs restrictive and regressive stereotypes of the domestic nurturing woman); Joan Williams, Gender Wars: Selfless Women in the Republic of Choice, 66 N.Y.U. L. REv. 1559, 1565-71 (1991) (arguing that Gilligan's difference feminism reinforces "neatly matched binary opposites integral to the covert gendering of the liberal pursuit of autonomy," and also diffuses any challenge to the system that precludes women from pursuing unconventionally autonomous paths).

100. See John M. Broughton, Women's Rationality and Men's Virtues: A Critique of Gender Dualism in Gilligan's Theory of Moral Development, 50 Soc. REs. 597, 635-36 (1983) (criticizing Gilligan's bimary logic and sharp contrasts between "male" and "fernale," and exposing the "crossovers" documented even in Gilligan's own interviews).

101. For instanee, "equal" disability leave makes no sense where only women bear and nurse children. See Christine A. Littleton, Reconstructing Sexual Equality, 75 CALIF. L. Rev. 1279, 1285 (1987) (arguing that male and female "differences," perceived or real, biological or social, should be costless). Cf. Cain, supra note 87, at 199 ("Women are most noticeably not like men when they are pregnant."). 
whether or not one believes an "ethic of care" is innately or uniquely feminine.

Perhaps the most telling critique of difference feminism, however, einerges from "dominance" feminism, the second branch of feminism considered in this Article. Dorninance feminism focuses on the power differential between women and men. It analyzes women's place in society by examining male subjugation of women, focusing particularly on sex and sexuality. Professor Kathryn Abrams has described dominance feminism as "that strand of feminist (legal) theory that locates gender oppression in the sexualized domination of woinen by men and the eroticization of that dominance through pornography and other elements of popular culture."102 Women's subjugation does not stem solely from discrimination or society's failure to appreciate women's roles and perspectives. ${ }^{103}$ Rather, dominance feminisin traces women's oppression to threats to women's safety and physical integrity. For dominance feminists, the organizing icon is not woman as mother, but woman as survivor of sexual violence and nember of a subjugated class. $^{104}$

Dominance feminists, concerned about the perpetuation of gender stereotypes and the unwitting division of a complicated political struggle into "sugar and spice" on the one hand, and "snails and puppy dog's tails" on the other, reject many of the tenets of difference feminisin. ${ }^{105}$ Dominance feminists worry that focusing on differences will merely

102. Kathryn Abrams, Sex Wars Redux: Agency and Coercion in Feminist Legal Theory, 95 ColUm. L. Rev. 304, 304 n.1 (1995).

103 Cf. Susan H. Williams, Feminist Legal Epistemology, 8 BERKELEY WOMEN's L.J. 63, 80-81 (1993) (arguing that a focus on women's differences "shifts attention away from asking about the institutional and cultural structures that create a norm and generate those differences").

104. See Catherine A. Mackinnon, Toward a Feminist Theory of the State 149 (1989) ("[A]ll women live all the time under the shadow of the threat of sexual abuse.").

105. Although dominance feminists realize the importance of supporting women, and believe that celebration of difference is a necessary step forward, they do not believe that women should be mired in gender-based stereotypes. No matter how positive those attributes are, as is the case with women's nurturing nature and empathy, they are also associated with subjugation. As Catharine MacKinnon has argued,

Beloved of left and right alike, construing gender as a difference, termed simply the gender difference, obscures and legitimatizes the way gender is imposed by force. It hides that force behind a static description of gender as a biological or social or mythic or semantic partition, engraved or inscribed or inculcated by god, nature, society (agents unspecified), the unconscious, or the cosmos. The idea of gender difference helps keep the reality of male dominance in place.

Catharine A. MacKinnon, Feminism Unmodified 3 (1987). MacKinnon also wrote:

The differences we attribute to sex are lines inequality draws, not any kind of basis for it. Social and political inequality are, I think, basically indifferent to sameness and difference. Differences are inequality's post hoc excuse, its conclusory artifact, its outcome presented as its origin, the damage that is pointed to as the justification for doing the damage after the damage has been done, the distinctions that perception is socially Id. at 8 . organized to notice because inequality gives them consequences for social power. 
provide fodder for those who wish to subjugate women. For them, celebration of women's ethic of care echoes traditional excuses for sexism that relied on some of the same qualities but used them to argue that women are too anecdotal, emotional, or spiritual for active participation in public life. Dominance feminists argue further that the "different voice" perpetuates male power by objectifying a male prototype and establishing it as the norm from which women are supposedly different. Focusing on women's necessary coping mechanisms in an oppressive patriarchal society, ${ }^{106}$ dominance feminists tend to see women's connectedness not as innate or socially desirable, but as a consequence of oppression. Women are nurturing because they have been forced and trained to be helpful, subservient, and sexually submissive to men. ${ }^{107}$ Dominance feminists assert that women's voices are not different, but muted, speaking in the whisper of subjugation.

Despite this serious disagreement, both strands of feminism are concerned with many of the same practical issues. Even though dominance feminists see identifiable gender differences as a cause for revolution, not celebration, they share with difference feminists a commitment to heeding women's stories and addressing the practical problems that women face. Ultimately, both strands provide valuable tools for analyzing law as it applies to these practical issues. Difference feminisin focuses on how law may not reflect or value the "different" ways women perceive and react, no matter how these differences originate. Dominance feminism, which searches for power discrepancies between men and women, is particularly concerned with women's physical safety and personal integrity. It analyzes how law may stifle or silence women. ${ }^{108}$

106. Catherine MacKinnon, the predominant dominance feminist, questioned Carol Gilligan about women's nurturance and ethics of care:

Why do women become these people, more than men, who represent these values? This is really very important. For me, ... the answer is the subordination of women. That does not mean that I would throw out those values. Those are nice values; everyone should have them....

What bothers me is identifying women with it. ... I am troubled by the possibility of women identifying with what is a positively valued feminine stereotype.

Dubois, et al., Feminist Discourse, Moral Values, and the Law-A Conversation, 34 BUFF. L. REv. II, 74 (1985).

107. See supra notes 105-106; $c f$. Kathy Alexis Psomiades, The Daughter's Dilemma: Family Process and the Nineteenth-Century Domestic Novel, 20 Signs 189, 190 (1994) (book review) (criticizing an author who "tends to take women's culture at face value as an eternally true natural force connected to women's biological and eultural role in nurturance").

108. Dominance feminists focus particularly on rape, pornography, harassment, and reproductive freedom, areas where inequality arises out of men's treatment of women's bodies. See Lisa R. Pruitt, A Survey of Feminist Jurisprudence, U. ARK. LITTLE Rock L.J. 183, I98 (1994) (explaining focus of MacKinnon's theory on legal contexts such as obscenity, rape, and reproductive freedom). Influenced by Marxism, dominance feminists also focus on economic differences, noting 
Both strands of femimism also question the notion of "objective" rules. ${ }^{109}$ So-called objective rules promote a male archetype and demote women to the position of an irrational other. ${ }^{110}$ Feminists reject the notion of "objectivity" because it assumes the existence of unsituated knowledge. Difference feminism identifies unsituated knowledge with male relational styles, while dominance feminism identifies the concept with male power. Nevertheless, both argue that the law's traditional reliance on the objectivity and neutrality of legal rules cloaks the oppression of women. ${ }^{111}$ They argue that any attempt to identify neutral reality or objective truth is fruitless, and that the assumptions underlying the goals of objectivity and neutrality are not only unfounded, but inevitably reflect gender power differences. ${ }^{112}$

The feminist critique of neutrality and objectivity is particularly important for a discussion of evidence law, because evidence law rests

that women's lack of political power reflects their dependent economic status. See generally MACKINNoN, supra note 105, at 48-49 (analogizing Marxist perspective to dominance feminism).

109. This tendency to believe that there exists an objective reality is certainly not unique to evidence law. As Leslie Bender writes, "Western culture teaches us that the patriarchal description of reality is not biased but neutral; that our knowledge and truths are not subjective, intersubjective, relative, or constructed from narrow perspectives but objective, scientifically based and universal ...." (footnote omitted). Bender, supra note 86 , at 9 .

110. See, e.g., Williams, supra note 100, at $72-74$ (noting that Cartesian epistemology equates knowledge with masculinity and the "thing known"-the object of knowledge-with femininity). Although a critique of neutral principles seems old-hat within the academy, it has not filtered its way into the understanding or practice of evidence law. Trial lawyers may plan strategies about whether it is better to have a woman as a juror or a man as an expert witness, but advocates have not generally questioned the neutrality of the rnles themselves. Evidence law tends to be very practical, which explains in part why until very recently so little of the current, very theoretical, jurisprudential debate has influenced thinking about evidence. See generally Michael L. Seigel, A Pragmatic Critique of Modern Evidence Scholarship, 88 Nw. U. L. Rev. 995 (1994).

111. Feminist epistemology offers aid to anyone challenging the notions of "neutral" evidence rules. As Professor Susan Williams explains, however, feminists cannot be satisfied with merely proving the subjectivity and indeterminacy of neutral rules. See Williams, supra note 100 , at 83 (noting that social constructionism may threaten wornen's political organizing by "decentering" the concept of "woman" and focusing on critique rather than transformation). Hand in hand with its critique of neutral principles, feminism operates from the axiom that oppression of women, or indeed of any unjustly subjugated oppressed group, is a social evil. See generally id. Social constructionism and post-modernism, as well as certain communitarian theories, also challenge the assumption that one can shed one's particularistic self and somehow engage pure logic to discover "the truth." See $i d$. at 69 (noting the social constructionist argument that "there are no 'brnte facts' to which human beings have access independent of their culturally contingent conceptual categories"). Feminism, however, adds unique elements in criticizing purportedly neutral rules, because feminists cannot adhere to the nihilistic unbridled relativism that some other critiques of Cartesianism generate. Feminist epistemology focuses on a particular excluded group: wonen. Feminism cannot tolerate all approaches as equally legitimate, or else it would have to tolerate the subjugation of women as one legitimate option. As Catherine MacKinnon has written, "feminism neither claims universality nor, failing that, reduces to relativity." Catherine A. MacKinnon, Feminism, Marxism, Method and the State, in Feminist Legal Theory, supra note 88, at 183.

112. See, e.g., Martha Albertson Fineman, Feminist Theory in Law: The Difference It Makes, 2 COLUM. J. GENDER \& L. 1, 12 (1992) ("Neutral treatment in a gendered world or within a gendered institution does not operate in a neutral manner."). 
upon an unspoken assumption that neutral rules and objective truth exist, and are accessible to the reasoning thinker who ignores emotion and other distractions. ${ }^{113}$ In applying feminist theory to evidence law, Professor Kit Kinports has noted that the reliance on logic and experience in evidence law presupposes a neutral vantage point and universal identity of experience. ${ }^{114}$ Kinports cites the rules of relevance, which, according to the advisory notes, avowedly rely on "logic" and "experience," as one example of evidence law's faith in its own objectivity. ${ }^{115}$ Without questioning or even noticing any of the underlying cultural assumptions, the rules of evidence imply that a social consensus exists about issues of logic and causation, and that members of society share largely similar experiences.

Even modern interdisciplinary evidence scholarship is subject to this critique. Although evidence scholars have been slow to learn from other disciplines, ${ }^{116}$ one key area in which interdisciplinary scholarship

113. Evidence scholarship has been criticized for perpetuating the fiction of neutrality and assuming the rationality of factfinders. See William Twining, Rethinking EVIDENCE: EXPLORATORY ESSAYS 71-77 (1990) (discussing the optimism in evidence laiv about the rationality of the judicial process). Twiniug has opined that evidence scholarship is generally "remarkably unsceptical in respect of its basic assumptions." Id. See generally William Twining, TheORIES OF Evidence: Bentham and Wigmore (1985) [hereinafter Twining, Theories of EVIDENCE ]. As Rosemary Hunter explains,

[T] he rules of evidence clearly embody Enlightenment epistemology. They privilege fact over value, reason over emotion, presence over absence, physical over psychological, perception over intuition. They are part of the same discursive regime of hierarchized dualisms that imparts greater cultural value to the masculine than to the feminine, partly through the association of "masculine" with attributes such as reason, presence, and perception and of "feminine" with emotion, absence, and intuition.

Hunter, supra note 2, at 129-30 (footnotes omitted); see also Stewart supra note 16, at 8 (evidence law reflects "more than a small touch of a highly rationalistic view of man").

114. See Kinports, supra note 2, at 431 (quoting Martha Minow and noting that although apparently neutral, relevance of evidence is "in the eye of the beholder").

115 Id. The Federal Rules of Evidence deem evidence relevant if it has "any tendency to make the existence of any fact that is of consequence to the determination of the action more probable or less probable than it would be without the evidence." FED. R. EviD. 401. This relevance standard is explained in the advisory committee's notes directing judges to rely on "principles evolved by experience or science, applied logically to the situation at hand." FED R. EVID. 401 advisory committee's note.

116. See William Twining, The Rationalist Tradition of Evidence Scholarship, in WeLL AND Truly Tried: Essays on Evidence in Honour of Sir Richard Eggleston 211 (Enid Campbell \& Louis Waller eds., 1982) (noting a revival of interest by evidence scholars in interdisciplinary scholarship where previously the study of evidence has been in "isolation"); Roger C. Park, Evidence Scholarship, Old and New, 75 MrN. L. Rev. 849, 849 (1991) ("The best-known interdisciplinary movements have, however, had little or no influence on evidence scholarship."); Seigel, supra note 110 , at 995 (arguing that "the major intellectual movements characterizing legal thought during the latter quarter of the twentieth century-including critical legal studies... and practical legal studies...-have left evidence scholarship virtually untouched"). Recently, however, scholars have begun expanding the very narrow and rule-based evidence scholarship. See Judy Cornett, The Treachery of Perception: Evidence and Experience in Clarissa, 63 U. CIN. L. Rev. 165, 168 (1994) (examining the evidentiary issues raised in Samuel Richardson's novel, Clarissa, from an interdisiplinary perspective); Seigel, supra note 110 (utilizing the philosophy of pragmatism to critique 
has flourished is the "new evidence" movement, which uses Bayesian probability theory to analyze questions of inference, proof, and the admissibility of hearsay. ${ }^{117}$ Like older evidence scholarship, however, these probabilistic models invite a feminist critique because they reinforce rather than undermine the detached, "objective" view of evidence. The emphasis on quantification and abstract mathematical models devalues the human aspects of discernment, including judgment, experience, and intuition. ${ }^{118}$ Not surprisingly, the new evidence movement has been criticized as conflicting with feminist methods and principles. ${ }^{119}$

\section{B. "He Said, She Said"-Toward a Feminist Critique of the Hearsay Rule}

Although this Article focuses on a feminist critique of an exception to the hearsay rule, it will briefly discuss possible avenues of feminist critique of hearsay as a whole. This analysis invites further thought and comment, but also serves as a precursor to the feminist critique of the excited utterance exception. To understand the significance of the exception, it is imperative that we analyze the rule from which it deviates.

By scanning hearsay law for a bias against the ethic of care, a feminist analysis could examine how the hearsay rule subverts relationships in and out of the courtroom. A feminist critique could also challenge the underlying rationale, construction, and application of the hearsay rule, highlighting its rigidity and its failure to account for cultural and gender bias. By probing for ways in which women's experiences and voices are ignored, a feminist critique could challenge the wisdom and the neutrality of the hearsay rule.

First, regarding its effects on relationships, the hearsay rule can be criticized for reinforcing unequal relationships and disempowering ordinary citizens. In contrast to an ethic of care, the hierarchical nature of the rule separates attorneys from clients, and divides courtroom officers from jurors. The hearsay rule-the secret handshake of the legal pro-

evidence scholarship); Wellborn, supra note 12 (summarizing social science materials, particuarly from psychology, and suggesting appropriate legal responses).

117. See Richard Lempert, The New Evidence Scholarship: Analyzing the Process of Proof, 66 B.U. L. REv. 439, 441 (1986); Peter Tillers, Intellectual History, Probability, and the Law of Evidence, 91 Mrch. L. REv. 1465, $1465-66$ (1993) (reviewing ShapIRo, supra note 1).

118. This criticism does not advocate that evidence should abandon modern science to help establish facts. Rather, it raises the concern that the mathematical formulas and logical proofs that allegedly model and predict reliability could supplant, rather than describe, the human elements of decision-making.

119. See generally Symposium, Decision and Influence in Litigation, 13 CARDozo L. REV. 253 (1991); L.H. LaRue, Stories Versus Theories at the Cardozo Evidence Conference: It's Just Another Metaphor to Me, 14 CARDozo L. REv. 121, $121-23$ (1992) (noting that probabilistic theories have been criticized as overly theoretical, acontextual, and non-representative of how jurors (or any one else, for that matter) make decisions). 
fession-mystifies lay people and serves to "alienat[e] them from the trial process." ${ }^{\prime 20}$ It perpetuates the power of a professional elite whose knowledge of its arcane rules makes lawyers indispensable, if incomprehensible. ${ }^{121}$ The hearsay rule, therefore, impedes connection or understanding. It serves to reinforce hierarchy and to perpetuate reliance on courtroom professionals, who tend to be predominantly male. ${ }^{122}$

Because the hearsay rule divides the jury from the actors in the know, the judge, the parties, and the witnesses all possess more information than they may reveal to the jury. As noted above, the hearsay rule rests on the assumption that formal, in-court, sworn testimony subjected to cross-examination is more trustworthy than out-of-court statements. ${ }^{123}$ Although trustworthiness is not the only justification for prohibiting hearsay, and arguments based on the social value and political right to confrontation and cross-examination abound, ${ }^{124}$ the primary argument

120. Kinports, supra note 2 , at 425 ; see id. at $423-25$ (discussing the complexity of evidence law in general and noting the "baffl[ing]" question of defining hearsay).

121. Lawyers who have learned the intricate matrix of the hearsay rules have little incentive to alter the system or reduce its mystique. See Ronald J. Allen, Commentary: A Response to Professor Friedman: The Evolution of the Hearsay Rule to a Rule of Admission, 76 MiNN. L. REv. 797, 801-02 (1992) (discussing the "potentially scandalous justification" for maintaining the hearsay rule-that it "protects the competitive advantage of those who know it"); Nance, supra note 9, at 284 n.274 (discussing the "real reasons for the Hearsay" Rule, including the "intellectual investment and a valuably exclusive expertise" of trial lawyers (quoting Hart \& McNaughton, Evidence and Inference in the Law, in EvidENCE AND INFERENCE 56 (D. Lemer ed., 1959))); Stewart, supra note 16, at 2 (noting the rejection of the Model Code of Evidence, which virtually abandoned the hearsay rule).

122. According to the American Bar Association, of 896,000 licensed lawyers in $1994,23 \%$ were women. See American Bar Association Commission on Women in the Profession, Women In the LaW: A Look at the Numbers 3, 29, 54 (1995). Although there has been a noticeable increase in female judges, as of 1991 only $9 \%$ of all judges were female. See id. at $29,51$. For other statistics on women in the legal profession, see Shirley S. Abrahamson, Toward a Courtroom of One's Own: An Appellate Court Judge Looks at Gender Bias, 61 U. CIN. L. REv. 1209, 1216 (noting that there is only one woman on the governing board of the National Board of Trial Advocates, that "only two percent of the lawyers certified by NBTA were women," and that of the 52 lawyers certified in Wisconsin, none were women); Carrie Menkel-Meadow, Symposium: The Future of the Legal Profession: Culture Clash in the Quality of Life in the Law: Changes in the Economics, Diversification and Organization of Lawyering, 44 CASE W. RES. L. REv. 621, 652 n.150 (1994) (noting that women are disproportionately underrepresented in bar leadership positions); Deborah L. Rhode, Gender and Professional Roles, 63 FordHAM L. REv. 39, 58 ("Women account for close to forty-five percent of new entrants to the profession, and over twenty percent of all lawyers, but only about eleven percent of the partners in the nation's 250 largest firms, eight percent of the federal bench, sixteen percent of the full professors in law schools, and seven percent of the law school deans.") (citations omitted). Although women make up approximately $40 \%$ of all managers, women hold only 5-7\% of senior executive positions. See GoOD FOR BuSINESS: MAKING Full Use of the Nation's Human Capital: Fact Finding Report of the Federal Glass Ceiling Commission 151 (Mar. 16, 1995), quoted in Kingsley R. Browne, Sex and Temperament in Modern Society: A Darwinian View of the Glass Ceiling and the Gender Gap, 37 ArIz. L. REv. 971, 977 n.21 (1995).

123. See supra notes 11-13 and accompanying text.

124. See, e.g., Eileen A. Scallen, Constitutional Dimensions of Hearsay Reform: Toward a ThreeDimensional Confrontation Clause, 76 MiNN. L. REv. 623, 626 (1992) (suggesting that societal dimension of confrontation clause should be given more weight by courts). 
against hearsay evidence rests upon the assumption that it is dangerously unreliable. The hearsay rule functions as a screening mechanism for jurors who are presumed to be unwilling or unable to weigh the trustworthiness of information appropriately. ${ }^{125}$ In this way, hearsay demonstrates deep disrespect for the jurors' imtelligence and common sense. ${ }^{126}$

Second, the hearsay rule can be criticized for its complexity, rigidity, and lack of reliance on context. Aside from the residual or "catchall" exceptions, ${ }^{127}$ the hearsay exceptions operate in rigid, highly formalistic categories: ${ }^{128}$ excited utterance, state of mind, recorded recollection, business records, dying declaration, and so forth. ${ }^{129}$ In practical terms, the hearsay rule and its many exceptions present an all-ornothing choice. The out-of-court statement offered to prove the truth of the matter asserted must conform to an exception or will be excluded, even if the statement is highly probative, seems trustworthy given the surrounding circumstances, and sheds unique light on the case. Conversely, if the hearsay statement fits within an exception, the evidence is admissible, no matter how untrustworthy the statement may appear. ${ }^{130}$ Although the parameters of the hearsay exceptions have been drawn with reliability in mind, they leave little room for arguing in a specific case that the evidence is in fact reliable. ${ }^{131}$ The organization of the hearsay rule and its exceptions restricts analysis of statements in context and instead may admit untrustworthy evidence just because it happens to fit

125. But cf. Cornett, supra note 116, at 181-182 (noting that depriving an individual of multiple sources of information rendered the individual's judgment unreliable).

126. Although the criticism that hearsay ignores common sense is certainly not new, the focus on relationships as part of practical reason is a unique contribution of feminism. As discussed below, jurors may not be ideal factfinders, but there is no reason to believe judges, who are still predominately privileged males, are any better.

127. See FED. R. Evid. 803(24), 804(b)(5).

128. For a benign view of the category approach, see Terree E. Foster, Present Sense Impressions: An Analysis and a Proposal, LoY. U. CHI. L.J. 299, 301 (1979) (explaining that "exceptions to the rule excluding hearsay have bcen carved for categories of statements which, as a class, neutralize one or more of the risks associated with unprobed testimony").

129. See FED. R. Evid. 803.

130. See Eleanor Swift, A Foundation Fact Approach to Hearsay, 75 CaL1F. L. REv. 1339, 1347-54 (1987) (criticizing the categorical approach). Of course the hearsay ban is only one hurdle within the framework of the Federal Rules of Evidence. Although an evidentiary fact may be admissible under the hearsay rule or qualify under one of the exceptions, the trial court may ultimately exclude the evidence under Rule 403. Under Rule 403, the trier of fact may exclude relevant evideuce if "its probative value is substantially outweighed by the danger of unfair prejudice, confusion of the issues, or misleading the jary, or by considerations of undue delay, waste of time, or needless presentation of cumulative evidence." FED. R. Evid. 403.

131. Only the residuals, statements against interest (in criminal trials) and the business and public records exceptions provide an independent screen for trustworthiness. See FED. R. Evid. 803(6), $803(8), 804(3)$. Elsewhere, Judge Becker and 1 have argued that all hearsay should be subjected to trustworthiness analysis. See Becker \& Orenstein, supra note 42, at 906-09. 
within a categorical exception. Such obstruction and rigid acontextual categories are inimical to the feminine voice. ${ }^{132}$

Third, on a substantive level, a feminist method can question the hearsay rule for its resulting loss of information and silencing of voices outside the formal courtroom setting. Hearsay evidence requires factfinders to rely on what people said out of court, and therefore draws on jurors' own experience, judgment, and intuition conceruing the usefulness of such out-of-court statements. As a practical matter, the hearsay rule's screening function means less evidence is available to the jury. Less evidence means less information and context. The hearsay bar robs jurors of a traditional device for learning about the world: hearsay. ${ }^{133}$ Furthermore, the type of evidence being lost is particularly important to women's traditional modes of communication and hence relevant to a feminist critique. Much excluded hearsay evidence consists of informal communication-gossip, casual statements to friends, on-the-scene-observations-as opposed to formal and formalized incourt sworn testimony.

This very type of evidence is crucial to women's oral traditions. Both difference and dominance feininists agree that women are more likely to develop non-traditional, informal networks of information (whether because of difference-based socialization, natural affinity, or lack of power). In the same vein, the attainment, dissemination, and evaluation of such second-hand information tends to fall within the

132. Professor Eleanor Swift has proposed a contextualized and fact-sensitive approach to hearsay reform. See Swift, supra note 130. Swift argues that these "categorical exceptions are substantive generalizations not formulated by the trier of fact, but drafted by judges and legislators to represent their collective beliefs about what kinds of hearsay statements are more likely to be reliable." Id. at 1351 . She highlights the fact that hearsay exceptions, premised on notions of trustworthiness or some functional equivalent of cross-examination, result in a mechanical and uncontextualized application of the exclusion. See id. at 1350-54.

Swift offers an intriguing, if unwieldy, alternative that addresses the problem of hearsay in functional terms. See id. at 1341. Hcr foundation fact approach "obligates the proponent of hearsay to produce a foundation witness" who would testify about the circumstances surrounding the declarant's testimony, including the declarant's "process of perceiving, remembering, and making a statement about a relevant event." Id. at 1342 . By providing this background information, Swift's proposal bypasses the abstract and rigid categories and instead focuses on the context in which the statements were made. With the additional information, jurors can evaluate the hearsay and rely on common sense means of determining reliability. Swift's approach has becn lauded as innovative and refreshing. See Christopher B. Mueller, Post-Modern Hearsay Reform: The Importance of Complexity, 76 MiNN. L. REv. 367, 402 (1992) (referring to Swift's proposal as "striking and original"). Swift's focus on context and her disavowal of abstract provisions in favor of contextual knowledge and informed practical decision making is feminist in approach, if not in name.

133. See infra Part 11I.C. As McCormick notes, "[m]uch of our learning comes in the form of hearsay." McCormick, supra note $7, \S 245$, at 428 . In a philosophical sense, all information is acquired through hearsay because to evaluate any picce of evidence, we must rely on statcments made by parents and teachers who helped us understand the world around us. In fact, banning this type of hearsay learning would be "epistemologically suicidal." Mary Morton, The Hearsay Rule and Epistemological Suicide, 74 GEo. L. J. 1301, 1305 (1986). 
practical experiences of women. Informal out-of-court statements are arguably more typical of women's different voice. Historically, women were deprived of political information, newspapers, and even literacy, and instead developed more informal methods, such as gossip and word of mouth, to learn about their worlds. ${ }^{134}$ To survive, women had to develop acute sensitivity to the moods and meanings of the people around them, and interpret events second-hand. ${ }^{135}$ Yet, such analytic tools are underutilized in a formal courtroom atmosphere, where the bar against hearsay controls. The hearsay prohibition, therefore, sacrifices potentially useful information packaged in a form familiar to and comfortable for women.

\section{Considering the Rights of Criminal Defendants}

Feminist arguments against hearsay are intriguing, yet they pose many difficult problems of practical application and theoretical consistency. A solution to the problems posed by the hearsay rule seems elusive, particularly in criminal cases, where the cumbersome, formal requirements are designed, in part, to protect criminal defendants. ${ }^{136}$ Certainly the hearsay rule would benefit from less jargon and a simpler structure. The feminist critique of hearsay outlined above, however, seems to demand more dramatic changes, many of which would unfairly disadvantage those accused of crimes.

A feminist call for case-specific determinations of admissibility of individual hearsay statements would be unfair to criminal defendants,

134. See Deborah Jones, Gossip: Notes on Women's Oral Culture, 3 Women's STud. INT'L Q. I93, 194 (1980) (defining gossip as an intimate personal style of discourse among women that serves in part as an informal communication network); id. at 197 ("Gossip is a staple of women's lives and the study of gossip is the study of women's concerns and values, a key to female subculture."); $c f$. Bernard J. Hibbitts, Making Sense of Metaphors: Visuality, Aurality, and the Reconfiguration of American Legal Discourse, 16 CARdozo L. REv. 229, 349-50 (1994) (comparing the traditional white Protestant male emphasis on visual imagery with the aural metaphors and traditions of (among others) women, African-Americans, and Jews, and noting the importance of "voice," hearing, and story to critical legal scholars). Certainly men gossip too, and less powerful people engage disproportionately in such informal methods of communication. See id. ("Compared to men, American women as a group have historically shared a greater proportion of their knowledge, experiences, and thoughts with one another by talking and listening, telling stories, and engaging in the intimate, detailed dialogue that men have pejoratively called 'gossip."') (citations omitted). But, as the heroine, Anne Elliot, proclaims in Jane Austen's Persuasion, "Men have had every advantage of us in telling their own story. Education has bcen theirs in so much higher a degree...." JANE Austen, Persuasion 230 (Zodiac Press I960) (1818).

135. For example, in an analysis of Samuel Richardson's novel Clarissa, Judy Cornett evaluates the heroine's ability to draw sound inferences and organize the evidence available to her. Professor Cornett observes that Clarissa presented a counter-example to the rational and formalistic evidence theories of her day that opposed hearsay: "For Clarissa and Anna, whose freedom of movement is limited by social convention, hearsay is an important source of information." Cornett, supra note I16, at 181.

136. See Park, supra note 9, at 54 (distinguishing the problems posed by hearsay in civil and criminal trials). 
who need some way of predicting and preparing for the evidence used against them. The less powerful criminal defendants are, the less likely they will be able to refute hearsay. Similarly, criminal defendants who come from disadvantaged circumstances will be less able to marshal the resources to collect or generate extensive hearsay testimony of their own, so a relaxed hearsay rule will favor the prosecution.

Although some feminists have occasionally joined forces with lawand-order advocates (for instance, in arguing for less defendantprotective evidence rules in cases of rape and other sexual violence), ${ }^{137}$ by and large feminists express empathy and concern for the rights of criminal defendants. ${ }^{138}$ Like women, criminal defendants as a class are often disadvantaged in their relationship to the legal establishment and frequently remain unheard in the courtroom. Feminists, who champion empathy and connectedness, may logically conclude that they must extend that same ethic of care to criminal defendants. ${ }^{139}$ Feminist insight drawn from the experience of subjugation and difference applies, therefore, to disadvantaged groups, such as the poor and African Americans, who are disproportionately represented among the accused.

Additionally, one might argue that the hearsay rule itself, which in criminal cases derives in part from the right to confront witnesses, reflects an appreciation for connectedness. According to confrontation theory, defendants have a right to look their accusers in the eye. A1though this right is largely adversarial, it also represents an intense social connection between two people ${ }^{140}$ (as opposed to the trial by affidavit that served as the original impetus for the right to confrontation). ${ }^{141}$

137. Feminists have even joined with the fundamentalist Christian Right to oppose pornography. See generally Catharine A. MacKinnon, Pornography, Civil Rights and Speech, 20 HARv. C.R.-C.L. L. REV. 1 (1985).

138. See, e.g., Susan Bandes, Empathy, Narrative and Victim Impact Statements, 63 U. CHI. L. REv. 361, 365, 386 (1996) (noting that emotion and storytelling can serve non-feminist ends and arguing that despite the value currently placed on empathy and narrative, victims' statements should be suppressed because they "evoke emotions inappropriate in the context of criminal sentencing"); Lynne N. Henderson, The Wrongs of Victim's Rights, 37 STAN. L. REv. 937 (1985) (discussing problems regarding movement in favor of victim's rights).

139. There is a respectable argument to the eontrary conceming crimes against women; however, as much as feminists can object to the solicitude that men accused of crimes against women often receive, feminists cannot jettison the presumption of innocence.

140. See Maryland v. Craig, 497 U.S. 836, 861 (1990) (Scalia, J., dissenting) (imagining a scenario where a father accused of child abuse cannot "sit in the presence of the child, and ... ask, personally or through counsel, 'it is really not true, is it, that I-your father (or mother) whom you see before you-did these terrible things?"').

141. See White v. Illinois, 502 U.S. 346, 361 (1992) (discussing the trial of Sir Walter Raleigh, who was accused of treason, based primarily upon the confession of a co-conspirator that was likely obtained through torture); see also JoHn GeORge PhILlMORE, History AND PRINCIPLES OF THE LAW OF EVIDENCE 157-68 (1850). See generally Kenneth W. Graham, Jr., The Right of Confrontation and the Hearsay Rule: Sir Walter Raleigh Loses Another One, 8 CRIM. L. BuLL. 99 (1972). 
In sum, a feminist critique of the hearsay rule provides reason to distrust the hearsay rule and, of course, insight into courtroom dynamics. However, given the countervailing concerns of criminal defendants, feminists probably should not argue for wholesale change of the hearsay rule protections. More promising, from a practical perspective, is the feminist critique of the excited utterance exception in the next Part. In addition to offering theoretical challenges and cultural insights, the critique also suggests practical changes in the excited utterance doctrine that can be achieved without undue hardship on criminal defendants.

IV

\section{That Same Old Voice is Yelling Again: A Feminist CRITIQue OF THE EXCITED UTTERANCE}

The characterization of a statement as an excited utterance reflects social milieus and highlights political tensions; what is considered "exciting" is constantly changing. Perhaps what society finds exciting or startling as a culture is part of what distinguishes a particular age. In the late nineteenth and early twentieth centuries, many cases involved excited utterances made by railroad employees about the cause of railway accidents. ${ }^{142}$ In more recent cases, gun crimes, automobile accidents, and emergency 911 calls figure prominently. ${ }^{143}$ Throughout the history of the doctrine, rape and other sexual violence, woman-battering, and child abuse examples arise repeatedly. ${ }^{144}$

This Part employs a feminist method to challenge the wisdom and fairness of the excited utterance exception, exposing some of the basic but hidden assumptions concerning how we, as a society, amass evidence and judge credibility, especially in cases of sexual assault. A feminist

142. In part, this was because under the agency law of the day that influenced evidence law, railway workers were not able to make admissions on behalf of their employers. See, e.g., Vicksburg \& Meridian R.R. v. O'Brien, 119 U.S. 99, 106 (1886) (considering statement describing conversation with engineer after train accident); Walters v. Spokane Int'l Ry. Co., 108 P. 593 (Wash. 1910) (evaluating statement by railway conductor regarding train derailment).

143. On incidents involving guns, see, e.g., United States v. Sewell, 88 F.3d 845, 847 (8th Cir. 1996) (evaluating excited utterance made while declarant saw carjacker put gun to victim's head); People v. Guam, 69 F.3d 369 (9th Cir. 1995) (evaluating excited utterance made minutes after gun pointed at declarant's head). For cases involving auto accidents, see, e.g., Tackett v. State, 670 S.W.2d 824 (Ark. Ct. App. I984) (holding excited utterance by accident victim who later died admissible for proving manslaughter and leaving scene of accident); Lovato v. Herrman, 685 P.2d 240, 241 (Colo. 1984) (holding rear end collision "qualifies as 'startling event"'). On 911 calls, see, e.g., Admissibility of Tape-Recording or Transcript of "911" Emergency Telephone Calls, 3 A.L.R.5th 784; cases include State v. Guizzotti, 803 P.2d 808 (Wash. Ct. App. 1991).

144. Professors Mueller and Kirkpatick have noted the special relationship between excited utterances and victim's statements. "[T] injures or claims the life of the speaker: Often he was in the best position to see and report, and excluding his statement would mean doing without good evidence and would have the unattractive consequence of shutting out the cries of the victim." MUELleR \& KiRKPATRICK, supra note 24, § 8.35 , at 1217 . 
method raises many questions about the excited utterance exception: Why does the law assume that everyone manifests stress in the same way? Who is likely to report immediately? Why do some people delay? Why is such delay assumed to be evidence of lying? Who is described by the excited utterance conception of stress? Who is excluded? Finally, what explains the longevity of the doctrine, particularly in light of the powerful psychological critique that diminished perceptiou may render excited utterances less trustworthy?

\section{A. The Myth of Universal Experience}

The excited utterance exception allows certain excited statements to be admitted as substantive evidence and elevates these out-of-court statements to the status of competent evidence. It thereby implicitly deems such statements and, arguably, those who uttered them, more reliable. As a logical matter, the exception also denigrates statements outside its purview, deeming such statements, and the speakers who made them, insufficiently trustworthy. The doctrine therefore favors spontaneous, visibly agitated speakers over other more quiescent, reflective, frozen, or passive ones. By privileging immediate, excited cries, the excited utterance contributes, albeit subtly, to our cultural and legal definition of credibility. ${ }^{145}$

Wigmore's own justification of the excited utterance exception provides a good starting point for a feminist critique of the doctrine. ${ }^{146}$ Wigmore rationalized the excited utterance rule as grounded in experience. He argued that the excited utterance "is based on our experience

145. See Stephen J. Schulhofer, The Feminist Challenge in Criminal Law, 143 U. PA. L. REv. 2151 (1995) (noting general tendency of criminal law to favor male concerns and male perspectives). Schulhofer critiques the radical feminist view that "even-handed inaction is nonetheless an affirmative policy that contributes to the subordination of women." $/ d$. at 2161 .

146. Interestingly, Wigmore, the chief proponent of the excited utterance exception, was adamant in his suspicion of women. In his treatise, Wigmore advocated that the court should delve into the mental health of all female complainants in rape cases. Wigmore was convinced that "female types of excessive or perverted sexuality" would dream up "imaginary sex incidents of which the narrator is the heroine or the victim." $3 \mathrm{~A}$ Wigmore, supra note $11, \S 924 \mathrm{a}$. He expressed concern for the "real victim," that is to say, the "innocent man." Id. Unsurprisingly, this view of survivors of rape and other sexual violence has prompted feminist comment. Although these assertions need no refutation, it is interesting to note that Wigmore relied on very scanty data to support his conclusions. See generally Leigh B. Bienen, A Question of Credibility: John Henry Wigmore's Use of Scientific Authority in Section $924 a$ of the Treatise on Evidence, 19 CAL. W. L REv. 235 (1983).

Wigmore's misogyny also influenced the development of excited utterance on a doctrinal level. Wigmore advocated strongly for additional protections on the defendant's behalf when the excited utterance exception arose in rape cases. He was partieularly concerned about cases of "bootstrapping," situations in which the evidence of the rape (a necessary preliminary to establish stress) was proven in part through the excited utterance itself. See 6 WIGMORE, supra note 11, $\$ 1761$. Because Wigmore distrusted women's rape reports, he warned against allowing the excited statement itself to prove the preliminary factor of an exciting event. See id. 
that, under certain external circumstances" the "stress of nervous excitement ... stills the reflective faculties ...."147 But upon whose experience did Wigmore rely? He relied primarily on case authority (of dubious persuasiveness) ${ }^{148}$ to demonstrate that the excited utterance doctrine possessed a venerable common law pedigree. To explain the doctrine's logic and policy, however, Wigmore appealed to unidentified "experience," which he assumed everyone shared. ${ }^{149}$ Without reflection or examination, Wigmore supposed that all people react to stress in the same way and that the excited utterance exception accurately describes that universal reaction. ${ }^{150}$

A feminist analysis questions the various unproved and unthinking assumptions embedded in the doctrine, demonstrating that the excited utterance exception does not, and indeed cannot, rest on "universal" experience. Although, as noted in Part II.C, the excited utterance exception has been criticized for its failure to account for speakers' diminished perception and memory when under stress, there has been little challenge to the rule's basic assumptions about how stress is manifested. Underlying the excited utterance doctrine is the notion that a normal person affected by a deeply stressful event would, within a brief time, utter an agitated statement concerning the event. By probing the identity of this "normal person," however, we discover that our fantasy declarant speaks with the voice of power and privilege.

\section{B. Rape Trauma Syndrome and a Different Voice}

The voice encapsulated by the excited utterance does not reflect many women's experiences. In particular, the doctrine's implicit cultural assumptions of how "normal" and "reliable" people communicate and react to stress do not comport with the practical experience of survivors of rape and other sexual violence. Indeed, the actual experience of many survivors could not be more different from the expectations encompassed in the excited utterance. Unlike the picture

147. 6 WIGMORE, supra note $11, \S 1745$, at 132-33 (emphasis added) (quoting Keefe v. State, 72 P.2d 425, 427 (Ariz. 1937)).

148. See supra note 32 and accompanying text (discussing Wigmore's scholarship and his miscitation and misinterpretation of important authority); see also Bienen, supra note 146, at 238 (noting that Wigmore looked to "academic sources which were never intended to support the propositions he put forward").

149. See Peter Tillers, Webs of Things in the Mind: A New Science of Evidence, 87 Mrcr. L Rzv. 1225, 1226 (1989) (discussing Wigmore's emphasis on the role of experience in determining relevancy). In support of the idea of a "universal" experience, Bentham declared that "experience is the foundation of all our knowledge." Twining, THEORIES OF EvidencE, supra note 113, at 29. In a similar vein is Justice Holmes famous dictum, "[T]he life of the law has not been logic: it has been experience." Oliver Wendell Holmes, JR., THE Common LaW 1 (1881).

150. Although it is true that feminism values experience, feminist method debunks the universalist notion of "experience," recognizing that even within our culture we do not share a common "experience." 
portrayed by the excited utterance exception, calling for a prompt utterance from a visibly stressed person, a victim of rape or other sexual violence is often numb and uncommunicative. Rape Trauma Syndrome ("RTS") describes this experience of many survivors of rape or other sexual violence who experience systematic withdrawal after the trauma. ${ }^{151}$

RTS documents typical behavioral manifestations of survivors of rape and other sexual violence. ${ }^{152}$ Often the survivor initially suffers disorganization; she may be hysterical or she may be withdrawn and subdued. The recovery from rape and other sexual violence is a slow process. As the survivor beings to reorganize psychologically, she experiences classic signs of post-traumatic stress, usually nightmares, phobias, and sexual fears. ${ }^{153}$ Only over time do most survivors process memories, begin to overcome the psychic numbing, and start talking to friends and counselors.

Ironically, these unexcited, reflective statements-described by RTS-that survivors make weeks or months after the trauma are not admissible under the current evidentiary scheme, even though their typicality makes them seem particularly trustworthy. ${ }^{154}$ The excited utterance exception, however, does not include these clinically observed, delayed, calm statements because of the time lag, as well as the declarant's lack of visible excitement. ${ }^{155}$ The rule has the psychology back-

151. The term was first coined by social workers Ann Burgess and Lynda Holmstrom in 1974. Ann Burgess \& Lynda Lytle Holmstrom, Rape Trauma Syndrome, 131 AM. J. PsYchiatry 981 (1974). Rape Trauma Syndrome was originally designed as a psychological tool to help treat survivors of rape and other sexual violence, and developed as an outgrowth of Post-Traumatic Stress

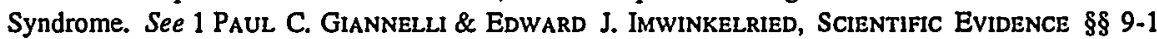
to $9-6$ (2d ed. 1993).

152. See Laura Etlinger, Comment, Social Science Research in Domestic Violence Law: A Proposal to Focus on Evidentiary Use, 58 ALB. L. REv. 1259, 1297 (1995) (citing recent research on women's reactions to rape).

153. See Nicole Rosenberg Economou, Defense Expert Testimony on Rape Trauma Syndrome: Implications for the Stoic Victim, 42 Hastings LJ. 1143, 1145-46 (1991); Deborah A. Dwyer, Expert Testimony on Rape Trauma Syndrome: An Argument for Limited Admissibility, 63 WASH. L. REv. 1063, 1064 (1988).

154. Professors John C. Yuille and Patricia T. Tollestrup cite a case study in which a woman who survived a sexual assault was unable to recall any details of the event for months after the attack, although eventually she was able to recall most details. See John C. Yuille \& Patricia T. Tollestrup, $A$ Model of the Diverse Effect of Emotion on Eyewitness Memory, in THE HaNDBOOK OF EMOTION AND MEMory: Research AND TheORY 209 (Sven-Ake Christianson ed. 1992). There is also psychological evidence that traumatic events can be emblazoned on one's memory, but for this to happen, the survivor must first have time to process the information. This controversial phenomenon is dubbed "fiashbulb memo[ry]." See Egeth, supra note 82, at 249. The traditional "flashbulb" question is "[w]here were you when you heard that Kennedy had been assassinated?" Id. Today one might ask, "where were you when O.J. Simpson was acquitted?"

155. See, e.g, People v. McConnell, 358 N.W.2d 895, 896 (Mich. 1984) ("The statements made by the complainant to her aunt some seven days after the criminal sexual conduct allegedly occurred were not admissible under the excited utterance exception to the hearsay rule because the statement did not revcal the requisite spontaneity ....”); Fitzgerald v. United States, 412 A.2d 1, 9 (D.C. 1980), 
wards. ${ }^{156}$ The rationale of the excited utterance exception rests on the theory that sincerity is guaranteed, because the declarant did not delay, or because any brief delay was mitigated by the stress that precluded fabrication by the declarant. ${ }^{157}$ But in fact, a rape survivor is more likely to be calm shortly after the incident and is more likely to delay reporting the crime. ${ }^{158}$

vacated, 443 A.2d 1295 (D.C. 1982) (holding declaration inadmissible as excited utterance if it "loses the character of a spontaneous utterance... and becomes a ealm narrative of a past event"); Commonwealth v. Pronkoskie, 383 A.2d 858, 863 (Pa. 1978) ("[T]he 'excited' nature of the utterance seems belied by the calm and unemotional manner in which they [sic] were made.").

In State v. Chapin, 826 P.2d 194 (Wash. 1992), the court held that the statement of a male rape survivor did not qualify under the excited utterance exception. The court determined that he "was unlikely to have still been in an excited state caused by the alleged rape" when he made the statement "within a day or so." Id. at 198. Also, earlier in the day, before making the statement, "he had been calm and had engaged in his usual activities. This increases the danger of fabrication. Consequently, the requirement of an excited state caused by the startling event is not met ...." Id.; $c f$. Baber v. United States, 324 F.2d 390, 393 (D.C. Cir. 1963) (weighing the factors creating a "borderline" case under the exception).

156. The divergence between popular presumptions of how "normal" people react to trauma and how women actually do react is even more troubling in light of the value our system places on demeanor evidence. See Stewart, supra note 16, at 23 (discussing psychological evidence that witness accuracy does not correlate with confidence); Wellborn, supra note 12, at 1077 (exploring perceived importance of demeanor evidence). Although our legal culture elevates demeanor evidence (in fact, one prominent explanation of the hearsay rule is the factfinder's need to evaluate demeanor), it turns out that untrained observers such as jurors do no better than chance at detecting lies or evaluating the perceptive skills of witnesses. See id. at 1080-82. Often those witnesses wliom factfinders believe are lying are merely exhibiting signs of stress, such as sweating, eyes darting, and fidgeting. This is called the "Othello error." (Othello killed his wife because he misread her stress for guilt). Id. at 1080 . Worse yet, despite psychological evidence to the contrary, people are generally confident that they can spot liars. See id. at 1081.

157. In United States v. Sherlock, 865 F.2d 1069 (9th Cir. 1989), one rape survivor "made her statement approximately one hour after the assault" and the other "made her statement even later." Id. at 1083. Both had spoken to several persons about the rape. The court explained that the women "had time to think about their actions and to invent an excuse about their late arrival at the dorm with alcohol on their breath." Id. The court ruled that the hearsay statements did not fall under the scope of the excited utterance exception. See id.

158. Dwyer notes that survivors of rape and other sexual violence often delay reporting, and the delays are longer when the woman knows her assailant. See Dwyer, supra note 153, at 1067 n.24 (citing Sedelle Katz \& Mary ANn MazUr, Understanding the Rape Victim: A Synthesis OF RESEARCH FINDINGS 188-90 (1979) (reviewing several studies indicating that "a substantial number of women delay reporting rape, and that the closer the relationship between the victim and the attacker the longer the delay)); Barbara Duffy Stewart et al., The Aftermath of Rape: Profiles of Immediate and Delayed Treatment Seekers, 175 J. Nervous \& MENTAL DISEASE 90, 92 (1987) (finding that "among a sample of highly distressed women who had been raped two months to over three years before requesting help, nearly $73 \%$ knew their assailants, as compared with only $50 \%$ of immediate treatment seekers"). Dwyer postulates that feelings of intense fear and helplessness associated with RTS may be exaggerated when the victim knows that her assailant could find her. See id.

Courts occasionally seem to acknowledge this truth. As the court explained in State v. Parker, 730 P.2d 92I (Idaho 1986), "A sexual assault is one of the more distressing experiences a person could have. The distress is likely to remain bottled up in the victim until she or he can talk about what happened." Id. at 924 . The court concluded: "Given that sexual assault crimes violate one's most intimate physical and mental feelings, the victim can reasonably be expected not to discuss the crime 
Courts debate the appropriate use of RTS evidence and are particularly reluctant to allow experts to testify that a survivor of rape or other sexual violence suffers from RTS in orcler to prove that the woman did not consent. ${ }^{159}$ Courts are more willing, however, to allow RTS evidence to explain delay, recantations, and seemingly normal or casual activities after the rape or other sexual violence. ${ }^{160}$ This debate on the scope of RTS expert testimony underscores the importance of using the knowledge gained from RTS in more fundamental ways. One essential benefit of RTS research for evidence law stems from the information rule drafters can learn and apply in devising evidence rules that reflect the experience of survivors of rape and other sexual violence, and allow their voices to be heard in the courtroom.

Rape Trauma Syndrome, therefore, serves two essential functions. ${ }^{161}$ From a psychological perspective, RTS assures survivors who experience

until meeting with a family member, close friend, law enforcement agent, or other trusted individual." Id. Courts tend to use this understanding, however, to stretch the time frame of the excited utterance exception, not to abandon the construct altogether.

159. See Hunter, supra note 2, at 147 ("[C]ourts have been reluctant to permit experts to testify that a rape complainant suffers from RTS in order to prove nonconsent; such evidence has bcen excluded on the grounds that it is unreliable, prejudicial, or entirely unhelpful to the jury.").

160. See Etlinger, supra note 152, at 1297-98. As Professor Toni Massaro explains, expert testimony concerning the syndrome can educate the jury about the nature of rape and how survivors respond to the traumatic event. See Toni M. Massaro, Experts, Psychology, Credibility, and Rape: The Rape Trauma Syndrome Issue and its Implication for Expert Psychological Testimony, 69 MiNN. L. REv. 395, 432-36 (1985); see also Morrison Torrey, When Will We Be Believed? Rape Myths and the Idea of a Fair Trial in Rape Prosecutions, 24 U.C. DAvis L. REv. 1013, 1067 (1991) (advocating expanded use of concept of expert RTS testimony to permit introduction of expert testimony concerning falsity of rape myths).

161. Rape Trauma Syndrome has its critics who, with merit, denounce its focus as a medical model that pathologizes the reasonable reactions of female victims of sexual violence by labeling their behavior as "symptoms" or "syndromes." See Susan Stefan, The Protection Racket: Rape Trauma Syndrome, Psychiatric Labeling, and Law, 88 Nw. U. L. REv. 1271 (1994) (arguing that women, who have encountered difficulty in being believed by doctors and psychologists, should be leery of placing rape in the care of mental health professionals). Stefan makes some excellent arguments, particularly in criticizing the medical and social work professions, but she neglects the overwhelming feeling of relief that survivors feel when they learn that their experience is normal. Although Stefan is correct that it is inappropriate to transform the observations of RTS into to a normative requirement, she undervalues its benefits. Despite legitimate concerns, RTS neverthcless can serve as an essential tool for feminists; it should not be abandoned.

Other critics worry about a potential "catch-22": that RTS has inerely replaced one set of expectations of the "proper" way for a survivor of sexual violence to react with another set of rigid expectations. Woinen can suffer because they don't fit patriarchal presumptions about victims of sexual violence, or if they do, then they are suspected of making it all up because they don't fit the RTS "requirements." See generally Economu, supra note 153, at 1170-71. Cf. Myma Raeder, The Double Edged Sword: Admissibility of Syndrome and Profile Evidence By and Against Batterers in Cases Implicating Domestic Violence, 67 CoLO. L. REv. (forthcoming 1996).

Still others doubt the scientific validity of RTS and argue that it should be used solely for healing survivors and not for proving guilt or even for vouching for the survivor's reaction as normal. Recent psychological literature, however, seems to credit RTS as a reliable description of the experiences of many survivors of rape and other scxual violence. See Patricia A. Frazier \& Eugene Borgida, Rape Trauma Syndrome: A Review of Case Law and Psychological Research, 16 L. \& Hum. BrHAv. 293, 
withdrawal and numbness that their reactions are normal. From a legal perspective, RTS can be used to educate the jury and, most importantly from the perspective of this Article, to inform rule drafters about the wide range of possible reactions to a sexual assault.

\section{Social Expectations of a Wronged Woman}

However RTS informs evidence law, we must question why a reaction to stress that is at odds with women's documented experience is nevertheless venerated by evidence law. Part of the answer lies in the fact that although the excited utterance does not describe the experience of women who have suffered rape or other sexual violence, it does comport with society's expectations of survivors of sexual violence. Doctrinally, there are strong indications that the excited utterance exception functions to promote social norms, articulating and enforcing social and cultural expectations of how women should react to these traumatic events.

Because of its uninformed and unrealistic doctrinal requirements, the excited utterance doctrine reinforces cultural presumptions about normalcy that enable society to dismiss women as liars. In requiring an excited and near-immediate response from the victim, evidence law implicitly dismisses those who do not fit the fixed pattern of credibility. The structure of the rnles insinuates that a reaction to a traumatic event that deviates from this prototype marks the declarant as unnatural, sneaky, vindictive, or otherwise unreliable. Indeed, the excited utterance exception is often justified because it purportedly prevents conniving and vindictiveness.

Studies confirm that survivors of rape and other sexual violence behave in ways, described by RTS theory, that seem counterintuitive to the average juror. ${ }^{162}$ The initial quietude-the deadly calm that survivors may display-conflicts with the cultural construct of the indignant respectable woman. As a consequence, survivors of rape and other sexual violence are often disbelieved because they do not fit the expecta-

299-300 (1992), cited in Etlinger, supra note 152, at 1297 n.204. Furthermore, even if the scientific evidence is unconvincing to some, the pattem described by RTS from anecdotal clinical observation alone provides another different type of "experience" that should co-exist alongside Wigmore's expostulation of the experience of stress.

162. See Stefan, supra note 161 , at 1340 n.365 (noting that "if a rape victim is too calm when reporting the assault to police, defense counsel will question her veracity or imply that she consented"); Torrey, supra note 160, at 1064-65, 1017-31 (reviewing psychological literature and summarizing popular perceptions of how rape victims are expected to behave). Studies of jury behavior and attitudes reveal poorly disguised hostility toward rape victims, whom juries view as assuming the risk of rape "by conduct such as drinking, wearing 'seductive' clothing, or accepting a ride with the assailant". Steven Bennett Weisburd \& Brian Levin, "On the Basis of Sex": Recognizing Gender-Based Bias Crimes, 5 Stan. L. \& Pol'y. Rev. 21, 31 (1994) (quoting Deborah L. Rhode, JUSTICE AND GENDER 248 (1989)). 
tion that a sincere woman genuinely wronged would cry out immediately. ${ }^{163}$

Underlying the notion that an excited cry is inherently credible is the assumption that a trustworthy woman would issue an immediate distressed cry. This assumption, dating back to Biblical law, distinguished the credibility of a victim who was raped in the city from one raped in the country. In the populated city, she would not be believed unless someone heard her cry out. ${ }^{164}$ The operation of excited utterance mirrors the Biblical standard. Although the contemporary excited utterance exception has no volume requirement, to qualify under the exception, a survivor of rape or other sexual violence must issue an excited statement very shortly after the event.

The requirement of prompt reaction and reporting in the Biblical tradition and the excited utterance requirement are particularly unreasonable in cases involving rape and other sexual violence. Many women suffer constraints, psychological and practical, that make it unlikely that they will fit the excited utterance paradigm. Survivors of sexual violence feel shame, face disbelief, and experience a realistic fear of rejection as "damaged goods." 165 Additional impediments arise from the historical silencing of women as a class and the notion that victims of sexual crimes somehow "asked for it," (a mean-spirited conclusion that only seems to apply to men when they are in prison). Furthermore, RTS research demonstrates that rape and other sexual violence causes tremendous internal turmoil and upheaval that lead many women to withdraw.

One indication that the excited utterance is more about social expectation and control than about psychology (however misguided) is that courts tend to admit out-of-court statements even when much time has passed for reflection, if the victim reported at the first real opportunity. ${ }^{166}$ In other words, even if the victim already had an opportunity to

163. Survivors of rape and other sexual violence are overwhelmingly women. Nonetheless, it is likely that the excited utterance also misdescribes the experience of men who are victims of sexual violence. The focus here, however, is on women, because women's welfare is central to feminism, the RTS evidence on which this Article relies was generated from the experience of women. Furthermore, all women suffer when an evidence rule serves to discount women's credibility.

164. See Deuteronomy 22:23-27.

165. See Ronet Bachman, U.S. Dep't of Justice, Violence Against Women 9 (1994) (discussing women's experience of fear and shame leading them to fail to report), cited in Myma S. Raeder, The Admissibility of Prior Acts of Domestic Violence: Simpson and Beyond, 69 S. CAL. L. REv. 1463 (1996).

166. See, e.g., United States v. Rivera, 43 F.3d 1291, 1296 (9th Cir. 1995) ("[T]ime lapse to be considered in [child sexual abuse] cases is not simply the time between the abuse and the declaration. Rather, courts must also be cognizant of the child's first real opportunity to report the incident.") (citing Morgan v. Foretich, 846 F.2d 941, 947 (4tb Cir. 1988)); State v. Peite, 839 P.2d 1223, 1230 (Idaho Ct. App. 1992) (emphasizing that "challenged evidence consisted of the very first statements" made by survivor after the rape, and ruling that these statements were admissible even though not 
calm down and reflect, (hence theoretically vitiating the spontaneity and assurance of reliability) her declaration is often nevertheless admissible if she reported the rape or other sexual violence as soon as possible. This approach echoes the doctrine of prompt complaint ${ }^{167}$ and elevates the fact of quick report over stress as a guarantee of sincerity. It reflects the high value associated with the woman's "proper" response in conformity with the construct of the believable injured woman and rewards women for acting in conformity with these social expectations.

\section{Denial and Power}

The observation that the excited utterance rule excludes reliable speakers, reinforces social expectations about how women should react to rape and other sexual violence, and fuels society's inclination to dismiss women as liars, builds upon a growing body of scholarship concerning women's experiences in the courtroom. In a recent article, Professor Kin Lane Scheppele explores how legal or courtroom "truth" is constructed by society to discount the voices of some women. ${ }^{168}$ Scheppele focuses on what she terms the "womanunfriendly habits"169 of courts in assessing evidence, examining why the "stories women tell in court, particularly in cases of sexualized violence like rape, sexual harassment, incest, and woman battering, are vulnerable to attack as unbelievable." ${ }^{" 170}$ She observes that abused and harassed

made immediately after the event); $c f$. McGugan v. State, 167 P.2d 76, 79 (Okla. Crim. App. 1946) (determining victim's failure to complain to driver who picked her up on highway and drove her to police station barred admission of victim's later complaint to police).

Although this willingness to extend the duration of excitement to fit within the excited utterance exception could merely reflect a doctrinal confusion with the doctrine of prompt complaint, which was admissible to shore up the "prosecutrix's" testimony in a rape case, it more likely reflects the deeper cultural assumption common to both doctrines that women, if they aren't hars, will report as soon as possible. See Ellis v. State, 6 So. 768, 770 (Fla. 1889) ("The female outraged should seek the first opportunity to complain, and the fact that she does complain goes to the jury as evidence....").

167. See infra note 213.

168. Kim Lane Scheppele, Just The Facts, Ma'am: Sexualized Violence, Evidentiary Habits, and the Revision of Truth, 37 N.Y.L. SCH. L. REv. 123 (1992). The title of the piece refers to the image of Sergeant Joe Friday from the old Dragnet television show-enjoining a hysterical woman to rid herself of emotion and describe a story chronologically and dispassionately, sticking to "just the facts."

169. Id. at 125. Professor Scheppele argues that even though the law "pretends to be above politics, prejudice, and partiality," it affects women unfairly. Id. at 166. In particular, she targets the "preference for first versions of stories," which "looks like a neutral rule" but "falls particularly hard on women." Id. at 169. She argues that it is a common phenomenon among women recounting a traumatic story for the truth to develop over time, particularly as the women consider and reinterpret events. A woman will recover signiflcant memory gaps as she gets stronger. Women who have been subject to sexual violence also exhibit symptoms of Post-Traumatic Stress Syndrome which "shatter[s] . . their sense of narrative coherence." Id. at 138-39 (citation omitted). On a more philosophical plane, Scheppele notes that disbelief of revised stories also indicates our judicial approach to truth as "singular, immediately apparent, and permanent." Id. at 127.

170. Id. at 123 . 
women exhibit many of the characteristics traditionally associated with liars-they remain silent for a long time after the abuse, procrastinate in reporting the incident, hesitate, change their stories, or sound equivocal because of self-blame. ${ }^{171}$ Scheppele uses the Anita Hill-Clarence Thomas hearings to demonstrate how delay in reporting hurts women's credibility. ${ }^{172}$ The senators, and even Thomas himself, relied on Hill's delay to question her memory, perception, and motives.

It is illuminating to speculate why courts often see what psychologists identify as women's typical reactions to stress and violence as evidence of lying. Two related theories offer possible explanations. First, as Scheppele suggests, the cultural construct of the lying, scheming female may be rooted in the psychological defense mechanism of denial. ${ }^{173}$ In psychoanalytic terms, denial is a way for the ego to repress painful facts and thoughts, ${ }^{174}$ crowd them out of consciousness, and avoid facing them..$^{175}$ Denial can happen on an individual level (such as an alcoholic who denies having a drinking problem) or can affect an entire society (such as German villagers who claimed to be unaware of Nazi genocide in nearby concentration camps). ${ }^{176}$

171. See id. at 126-27.

172. As Scheppele notes, there are many explanations for delay in reporting and changes in a story. Delay may arise from an attempt to solve, defuse, or negotiate a problem. See id. at 149. Once a sexually harassed woman has been fired, she has no further incentive for silence. Her "delayed" disclosure is not necessarily prompted by revenge, but by the fact that she has nothing left to lose. The issue of the subtle (and not so subtle) expectations we have of how womcn react to stressful situations has been played out in battered woman syndrome as well. See generally Mahoney, supra note 5 (comparing the arguments made for disbelieving Hill with traditional ways of discrediting women who stay in abusive relationships). Professor Mahoney draws on the rhetoric of the Clarence Thomas hearings to critique the ways physically abused women are treated and their stories are heard. Like Professor Scheppele, Professor Mahoney examines the hearings and observes how women's credibility is measured by a faulty set of assumptions. The battered woman is held to account: Why didn't she leave? Why didn't she do something? Or at lcast say somcthing? The presumption is that it could not have been that bad because the woman chose to stay in the relationship. Therefore, the woman's account of the battery is discounted. See id. at 1285-87.

173. See Scheppele, supra note 168, at 138-45 (describing how rape survivors alter their stories over time in order to deal with this trauma).

174. See David S. Caudill, Freud and Critical Legal Studies: Contours of a Radical Socio-Legal Psychoanalysis, 66 IND. L. J. 651, 658-59 (1991).

175. See id at 675 (quoting David M. Trubek, Where the Action Is: Critical Legal Studies and Empiricism, 36 STAN. L. REv. 575, 607 (1984), who has characterized all legal thought as "a form of denial, a way to deal with perceived contradictions that are too painful for us to hold in consciousness"); Martha R. Mahoney, Legal Images of Battered Women: Redefining the Issute of Separation, 90 MICH. L. REv. 1, 11 (1990) (discussing denial of domestic violence and defining denial as "a defense mechanism well recognized in psychology that protects people from consciously knowing things they cannot bear to reckon with at the time"); see also Christine Adams, Mothers Who Fail to Protect Their Children from Sexual Abuse: Addressing the Problem of Denial, 12 YALE L. \& POL'Y REv. 519, 521 (1994) ("Denial is a psychological defense mechanism that a person uses to screen out distressing realities and the painful feelings they cause.") (citing TABER's CYCLOPEDIC Medical Dictionary 472 (Clayton L. Thomas ed., 16th ed. I989) (further defining denial)).

176. See Caudill, supra note 174, at 661 (stating that psychoanalysis "contains the possibilities for an approach that analyzes the mechanisms by which the social world enters into the experience of 
Women's stories of rape and other sexual violence, battery, and harassment paint a terrifying portrait of women's everyday lives, ${ }^{177}$ and are often too painful to hear. Rather than believe that women are in danger, society looks for psychological comfort by engaging in denial. ${ }^{178}$ The overwhelming brutality and violence against women invites society to discredit women who as survivors, litigants, or political activists agitate to have their stories heard. ${ }^{179}$ Society resorts to the more psycliologically reassuring conclusion that the victim must be lying, or at least exaggerating. ${ }^{180}$

The process of denial leads to distortion. In order to deny women's experiences, we as a society reconceptualize and redefine violence against women so that the only "real rapes"181 are those perpetrated by the relatively unusual scenario of an attacker hiding in the bushes, ${ }^{182}$ and the only real traumas are those that elicit an immediate or near-immediate cry. ${ }^{183}$ By denying the staggering statistics of violence

each individual, constructing the human 'subject' and reproducing itself through the perpetuation of particular patterns of ideology") (quoting S. Frosh, The Politics of Psychoanalysis: AN Introduction to Freudian and Post-Freudian Theory 40 (1987)). See generally Daniel Goleman, Vital Lies, Simple Truths: The Psychology of Self-Deception 175-79 (1985).

177. According to the Surgeon General, violence from men is the single greatest health threat to American women. See Weisburd \& Levin, supra note 162, at 32 (1994). Data show that women are far more likely to be targets of gender-related violence, sexual abuse, or intimidation. See The Violence Against Women Act of 1991, S. REP. No. 102-197, 102d Cong., 1st Sess., at 33-34 (1991) [hereinafter Violence Against Women Act]; Caroline Wolf Harlow, U.S. Department of Justice, Female Victims of Violent Crime 1 (1991); Angela Browne \& Kirk R. Williams, Gender, Intimacy, and Lethal Violence: Trends from 1976 Through 1987, 7 GENDER \& Soc'y 78 (1993). See generally Mary I. Coombs, Telling the Victim's Story, 2 TEx. J. WoMEN \& L. 277 (1993) (claiming that the legal system will not acknowledge the wide variety of circumstances in which sexual violations occur); West, supra note 90 (arguing that women experience suffering that men do not, and that the legal system trivializes these gender-based sufferings).

178. See Mahoney, supra note 175, at 3 ("For actors in the courtroom drama, the fiction that such violence is exceptional allows denial of the ways in which domestic violence has touched their own lives."); Scheppele, supra note 168, at 142.

179. See Joan S. Meier, Notes from the Underground: Integrating Psychological and Legal Perspectives of Domestic Violence in Theory and Practice, 21 HoFsTra L. REv. 1295, 1311 (1993) (skepticism of women's stories "is far easier than acceptance of the reality that so many men are so dangerous, and that there is little (or nothing) many women can do on their own to be safe").

180. Cf. Final Report of the Michigan Supreme Court Task Force on Gender Issues IN THE Courts 24 (1989) (revealing the belief that women lie or exaggerate about domestic violence), cited in Hunter, supra note 2, at n.263.

181. See SUSAN ESTRICH, REAL RAPE 1-7 (1987) (describing differential treatment of "real rape" and "simple rape" and arguing for a new understanding of rape that "recognizes that a 'simple' rape is a real rape").

182. In fact, most women are raped by people they know. See Weisburd \& Levin, supra note 162 , at 30 (citing studies that concluded that $70-80 \%$ of rapes are committed by acquaintances of the victim).

183. See Stefan, supra note 161, at 1319-20. This cultural expectation also explains the tendency to describe RTS as a psychological adjustment problem, rather than as a natural reaction. See also supra notes 151-153 and accompanying text. 
against women (which is always easy to do), ${ }^{184}$ and by ignoring the stories of individual women (harder, but possible), society is spared the pain of empathizing with women and the difficulty of changing behavior and attitudes. Righteous men are spared facing the fact that they may not be able to protect their wives, sisters, daughters, or friends. Violent men are spared facing their crimes. Women are spared the realization of their own vulnerability to rape and other sexual violence.

Second, in addition to, or perhaps as part of denial, society's response to women survivors of sexual violence is also affected by the myopia of power. Functionally, society's construction of women's experience serves to reinforce the culture of the dominant group, mirroring the experience and world view of those in power. Indeed, this focus on the power differential between men and women is the hallmark of dominance feminism.

The current construct of a "credible woman" subtly reinforces the current power dynamics between the sexes, demanding that female survivors of sexual violence display stress in a socially acceptable fashion and report the attack (to male authority figures) immediately. Because it deviates so markedly from women's reported experiences, this construct, as a functional matter, perpetuates suspicion of women, feeds social denial, and allows violence against women to continue.

An analysis from a power perspective helps to explain silence and delay of victims of rape and other sexual violence. ${ }^{185}$ In addition to the

184. "A single death is a tragedy, a million deaths is a statistic." JoHN BARTLETr, FAMILIAR QuOTATIONS 766:11 (15th ed. 1980) (attributed to Joseph Stalin). Cf. Weisburd \& Levin, supra note 162 , at 28 (stating that a vast majority of those who murder women are present or former intimate partners). As Professor Deborah Rhode acknowledges, rape may be the most underreported of all crimes and "[e]stimates of the percentage [of rapes] reaching police attention range from 5 to 50 percent, and much appears to depend on how one surveys possible victims." RHODE, supra note 162, at 246; see Stefan, supra note 161, at 1281-85 (discussing various methods of measuring rape including FBI reports, the National Crime Victimization Survey, and various other surveys). Fear of rape dramatically affects women's exercise of their personal and civil rights. As the Report of the Senate Judiciary Coramittee on the Violence Against Women Act recently noted,

$[O]$ ne recent study showed that three-quarters of women never go to the movies alone after dark because of the fear of rape and nearly 50 percent do not use public transit alone after dark for the same reason. Women accommodate their fears by restricting their hehavior. Due in large part to the fear of rape, a woman is eight times more likely than a man to avoid walking in her own neighborhood after dark.

Violence Against Women Act, supra note 177, at 38-39.

185. This focus on power is also supported by linguistic and anthropological studies that indicate gender and class differences in courtroom speech patterns. These studies document that women and other subordinated groups employ speech patterns and communication strategies that are perceived as less credible. See Barbara Bezdek, Silence in the Court: Participation and Subordination of Poor Tenants' Voices in Legal Process, 20 Horstra L. REv. 533, 583 (1992) (citing RobIN Lakoff, Language and Woman's Place (1975)) (discussing "powerless speech"); John M. Conley et al., The Power of Language: Presentational Style in the Courtroom, 1978 DUKE L. J. 1375, 1380 (defining a powerless speech style and noting that the style is used more frequently by female witnesses); Peggy C. Davis, Contextual Legal Criticism: A Demonstration Exploring Hierarchy and "Feminine" Style, 66 N.Y.U. L. REv. 1635, 1647-54 (1991) (discussing discourse patterns associated with gender, 
psychic numbness and self-blame they experience, ${ }^{186}$ their delay may stem in part from powerlessness, and in part from an awareness that their claims will not be vindicated or respected. The survivor who becomes numb to her terror for weeks after the rape or other sexual violence, (much like the wife who remains with her abusive husband ${ }^{187}$ or the highly placed assistant who tolerates sexual harassment), ${ }_{1}^{188}$ contrasts sharply with the image of the powerful excited utterer perpetuated by evidence law. These women do not cry out quickly in excited proclamations; instead they delay making formal reports or even telling anyone. Given the structure of evidence law, however, this very response of the less powerful further undermines their claims. Consequently, their silence and delay discredits them even more. Because of this delay, they are perceived as brooding, conniving, and untrustworthy, rather than spontaneous, instinctive, and honest; there is little recognition of their shame, their fear of making a report, or their need to sort through emotions and options. ${ }^{189}$

Thus, the excited utterance makes sense only for those who feel safe enough to issue a cry of protest, and secure enough that the cry will be taken seriously..$^{190}$ One can see this as a conspiracy-it certainly has effectively squelched women's voices-or one can see it, as this author does, as part of the hubris of power. Those who possess power may be oblivious to the nature of that power, understanding their elevated status as the natural order of things. Like Wigmore, they rely on their own experience-and assume its universality. As beneficiaries in the power hierarchy, they assume its correctness, fairness, and inevitability. As winners, they are not prompted to question whether a style of discourse

including signs of uncertainty); Lucie E. White, Mobilization on the Margins of the Lawsuit: Making Space for Clients to Speak, 16 N.Y.U. Rev. L. \& Soc. Change 535, 543 n.35 (1987-88) (citing Conley et al., supra). Hallmarks of this powerless speech include tentativeness, hedging, hiding statements within questions, and using modifiers that tend to undermine the content of the statement. The pattern serves to reinforce the hierarchy of speakers and invites the histener to discount the speaker's personal communication and importance. See Bezdek, supra, at 584-85 (citing Lakoff and studies by William O'Barr in which jurors asked to assess witnesses' testimony after hearing tapes of identical transcripts but im powerful and powerless styles assessed the powerless style speakers as less credible).

186. See, e.g., Dwyer, supra note 153, at 1067 n.24 (discussing parallels between Post-Traumatic Stress Syndrome and RTS); text accompanying notes 151-153.

187. See generally Mahoney, supra note 175.

188. See generally Susan Estrich, Sex at Work, 43 STAN. L. REv. 813 (1991).

189. Social science research has demonstrated that women's communication styles tend to be perceived as less credible generally. See Hunter, supra note 2, at 165 (noting that women's speech patterns, "such as 'ums,' rising intonations, and hesitancy, are associated with powerlessness").

190. See id. at 127 (emphasizing the themes of admissibihty and credibility and arguing that first women's stories be allowed into court and that "then [courts] must take these stories seriously"). Hunter notes that "[t] here are also good reasons why women may fail to report abuse at the time it occurred: they may feel that complaints are hopeless or may be traumatized or intimidated into silence." Id. at 160 . 
that works for them may not be universal. This inability to see other perspectives (born of the lack of need to do so) is a failure of empathy. ${ }^{191}$ It also reinforces denial. Those who cannot speak in the language of power will not be as readily heard; if stories of rape and other sexual violence are not heard, the problem can easily be denied.

Practically speaking, a powerful person exposed to a great affront such as sexual harassment or physical violence would respond decisively and without delay. Those in positions of power rail at unjust treatment, in part, because they possess the conviction that they deserve better. Furthermore, as members of a dominant class, they have a reasonable expectation that their rights and concerns will be addressed. ${ }^{192}$ Their experience in negotiating the legal system and other social institutions promotes their confidence that they can redress wrongs perpetrated against them.

Thus, the excited utterance exception may incleed delineate the hallmarks of believability in describing the perspective of certain dominant and powerful speakers. Because they are dominant and have control over their lives, such speakers confront few circumstances that challenge their worldviews; nothing in their lives has prompted them to notice that their experiences are not universal. But it is these very assumptions of normalcy, objectivity, and universality that feminism challenges.

\section{E. Extending the Excited Utterance Doctrine}

Two points emerge for future consideration. First, although the starkest examples of disbelieving women surround rape and other sexual violence, it would be interesting to apply this analysis to other events. One obvious way to extend this analysis is to apply it to other areas of law in which women are not believed, and myths of female wrongdoing are used to blame the victim, such as domestic battery, sex-

191. For a wonderful definition and discussion of empathy, see Lynne N. Henderson, Legality and Empathy, 85 Mich. L. REv. 1574, 1579-82 (1987) (identifying three aspects of empathy or empathic capacity: 1) the capacity to perceive others as sharing one's own goals, interests, and feelings; 2) the imaginative experience of the situation of another; and 3) the response that accompanies experiencing another's distress, which may (but not must) lead to action to ease the pain of another).

192. Given this power-based explanation, it is reasonable to believe that women of color, who have less power and less claim on the ruling elite, may be doubly disbelieved. Some women of color may also be hampered by divided loyalties in issues of gender politics that seem to pit white women against African-American men. Recent cases involving allegations of rape or violence against famous African-American men (such as Mike Tyson and O.J. Simpson) have pitted allegiance to race against allegiance to sisterhood. See Robert García, Rape, Lies and Videotape, 25 LoY. L.A. L REv. 711, 721 r.38 (1992) (citing Harris, supra note 93, at 598-601 (1990)) (discussing black women's conflict between victimization by rape and empathy for black men who have been victimized by society); Valerie Smith, Split Affinities: The Case of Interracial Rape, in CoNFLICTS IN Feminism 271, 278-84 (Marianne Hirsh \& Evelyn Keller Fox eds., 1990). 
ual harassment, and stalking. Indeed, one could postulate that the critique could apply to all utterances made by women concerning startling events. If the willingness to make a quick, excited declaration reflects a typically male conversational style, the excited utterance rule would fail to describe the experiences of female witnesses in all types of exciting events.

The problem with this extension of the doctrine, however, is that the delay and hesitation produced by some startling events might be less pronounced than in cases of sexually related crimes, where a woman feels her general powerlessness mixed with the shame associated with sexual assault or harassment. Arguably, a woman might fit more closely into the "reliable" observer mold delineated by the excited utterance exception if she is involved in a traffic accident than if she survives sexual violence. As a witness to a traffic accident, her status is less subordinate, her person is not violated, and the woman may feel powerful enough to speak in the voice of the empowered. In addition, society's psychological need to deny her story is diminished in the case of a traffic accident, as compared with a tale of sexual violence.

A second point for further thought involves extending the analysis to other groups. If, indeed, the excited utterance exception provides an example where the dominant culture misunderstands or ignores the less powerful, this feminist critique of the excited utterance exception could logically extend to other oppressed groups, such as racial minorities, homosexuals, or the poor, whose history of subjugation and cultivation of different voices may influence their ability to fit into the evidentiary mold of the credible speaker. ${ }^{193}$ Suspicion of delay is not exclusively a problem for women, but may in fact affect anyone who is made to feel less powerful through the trauma of violence or unpleasant and unbidden sexual or physical attention. Hence, this part of the critique could apply to some male victims of violence or harassment, or any group that has less access to and confidence in the justice system.

Whatever this feminist critique may teach us about communication in general, and however it may extend to other groups and other exciting events, it is clear that evidence law must be modified to address the disparity between RTS and the current structure of the excited utterance exception. The excited utterance exception disserves the practical needs of women by relying on an underinclusive, arguably patriarchal view of how people react to the stress of rape or other sexual violence. ${ }^{194}$ We

193. This hypothesis is supported by the research on powerful and powerless speech. See White, supra note 185 , at $542-44$ (discussing the power and perceived credibility of the poor); Bezdek, supra note 185 (same).

194. Others have criticized the exception as over-inclusive in that it admits statements that are not necessarily accurate or reliable, see Swift, supra note 130 , at $1347-54$, but that issue does not arise here, except insofar as it adds irony to the exclusion of women's voices. 
cannot continue to rely on unsound cultural intuitions that reflect gendered notions of normalcy and credibility. If the purpose of the excited utterance rule is, in fact, to assure credibility, it is essential that the law reflect what psychology has told us about the experience of women. We must listen to the observations of psychologists and the self-reporting of women regarding how survivors of sexual attacks actually respond. Furthermore, this call for change does not imply that psychology or even feminism is fully free of cultural bias and sexism. What follows is a proposal that attempts to confront some of the entrenched distrust of women that underlies the evidence rules, and to address problems with the current doctrine, reflecting current knowledge about the psychology of survivors of rape and other sexual violence.

\section{$\mathrm{V}$}

\section{A Proposal for Amending the Excited Utterance Rule AND FOR ESTABLISHING A NEW HEARSAY EXCEPTION FOR SURVIVORS OF RAPE AND OTHER SEXUAL VIOLENCE}

This Article proposes a change in the current excited utterance rule $^{195}$ and outlines a related new hearsay exception for survivors of violent or sexual crimes. The proposed new exception reflects the insight that because sexual violence derives from power plays by the perpetrator and often induces shame on the part of the victim, it is unlikely that many survivors, especially women (but not exclusively so), will report immediately. The admission of such survivors' hearsay statements about the rape or other sexual violence, regardless of the timing of the report, would render evidence law more inclusive and psychologically informed.

As a doctrinal matter, the proposed changes straddle the division between Rule 803 hearsay exceptions, for which the declarant's availability is immaterial, and Rule 804 hearsay exceptions, for which the declarant must be shown to be unavailable. The revised excited utterance rule would create a preference for the victim's availability in court, but would also admit victims' hearsay statements where the victim was proven to be unavailable. ${ }^{196}$ The proposed rule reads as follows:

195. Because the excited utterance exception as it is currently drafted probably does serve some speakers and has survived for generations, I am loathe to abandon it entirely. The feminist critique, like the psychological one, stems from concerns that the doctrine is flawed and underrepresentative, not that it is entirely without value. Instead, my proposal retains the doctrine with modifications that acutally increase its fairness to the accused.

196. Cf. Michael L. Seigel, Rationalizing Hearsay: A Proposal for a Best Evidence Hearsay Rule, 72 B.U. L. REv. 893, 897, 928-38 (1992) (stressing the importance of making available declarants subject to cross-examination and proposing a hearsay rule that would take into acount the prosecutor's ability to make declarants available). 
The following statements are not excluded by the hearsay rule if the declarant is available for cross-examination concerning the statement or if the declarant is proven to be unavailable under Rule 804(a):

a) Excited utterance. A statement relating to a startling event or condition made while the declarant was under the stress of excitement caused by the event or condition.

b) Sexual violence survivor's statement. A statement concerning a sexual assault, made by the survivor concerning the event or its effect on the survivor. Where the survivor is unavailable pursuant to Rule 804(a), the survivor's statement is admissible only if the court finds that circumstances surrounding its making indicate the trustworthiness of the statement. For the purposes of this exception, snrvivor shall mean an adult who has experienced sexual assault as defined by Federal law or law of a State (as defined in section 513 of title 18, United States Code) that involved-

(1) any conduct proscribed by chapter $109 \mathrm{~A}$ of title 18 , United States Code;

(2) contact, without consent, between any part of the defendant's body or an object and the genitals or anus of another person;

(3) contact, without consent, between the genitals or anus of the defendant and any other person's body;

(4) deriving sexual pleasure or gratification from the infliction of death, bodily injury, or physical pain on another person; or

(5) an attempt or conspiracy to engage in conduct described in paragraphs (1)-(4).

The victim need not actually be alive or available to qualify as a survivor.

c) Notice to the accused in a criminal case. In a criminal case, the prosecutor must give reasonable written notice in advance of the trial or hearing, or during trial if the court excuses pre-trial notice on good cause shown, of the intention to introduce an excited utterance or a survivor's statement.

\section{A. Doctrinal Changes}

The proposal under subsection (a) differs from the current excited utterance in two major respects: availability of the declarant and notice to the defendant. Currently, the excited utterance exception, as codified under the Federal Rules of Evidence, applies whether or not the declarant is available to testify. Astoundingly, this means that under the current rule the declarant could be sitting in the courtroom and the hearsay could nevertheless be used in preference to in-court testimony without 
any opportunity for the accused to confront the declarant. ${ }^{197}$ The proposed revision to the excited utterance rule allows the opposing party to confront and cross-examine the declarant concerning the statement whenever the declarant is in fact available. In most cases covered by this proposed amendment to the excited utterance, the survivor will testify and the criminal defendant will have an opportunity to cross-examine the survivor and the testifying witnesses, and will suffer no unfairness. ${ }^{198}$ Furthermore, the criminal defendant will receive notice from the prosecutor pursuant to section (c). From the perspective of a criminal defendant, this is an improvement over the existing excited utterance rule.

To offer an excited utterance where the declarant does not testify, the prosecution must show that the declarant is unavailable. The standard for unavailability is set out in Federal Rule of Evidence 804(a) and includes incompetency and incapacity. ${ }^{199}$ The most frequent causes of declarant's unavailability involve subsequent interference with her ability to testify (such as sickness, intimidation, or death), or, in the case of a very young child, incompetence to testify. Although there is a strong argument that emotional incapacity to face the perpetrator should constitute unavailability for traumatized adults as well as children, that question is best left for another day. If evidence law were to allow an adult's unavailability to derive from emotional trauma, the declarant's statement would obviously be admissible only upon a particularized showing that such testimony would create trauma for the declarant

197. This is reminiscent of Sir Walter Raleigh's objection that his accuser (whose testimony was summarized through affidavit) was "hard by" and should have been made available for questioning. 1 Knight's Crim. Trials 418 (1932), cited in John KaPlan ET al., Cases and Materials on EVIDENCE 83-84 (7th ed. 1992).

198. Although this is not exactly equivalent to confronting the declarant at the time she makes the statement, it is very close, and the Supreme Court has approved such subsequent confrontation where the witness takes the stand. See Califomia v. Green, 399 U.S. 149, 159 (1970) (stating that "the inability to cross-examine the witness at the time he made his prior statement cannot easily be shown to be of crucial significance as long as the defendant is assured of full and effective crossexamination at the time of trial").

199. Federal Rule of Evidence 804(a) provides:

Definition of unavailability. "Unavailability as a witness" includes situations in which the declarant-

(1) is exempted by ruling of the court on the ground of privilege from testifying concerning

the subject matter of the declarant's statement; or

(2) persists in refusing to testify conceming the subject matter of the declarant's statement despite an order of the court to do so; or

(3) testifies to a lack of memory of the subject matter of the declarant's statement; or

(4) is unable to be present or to testify at the hearing because of death or then existing physical or mental illness or infirmity; or

(5) is absent from the hearing and the proponent of a statement has been unable to procure the declarant's attendance (or in the case of a hearsay exception under subdivision (b)(2),

(3), or (4), the declarant's attendance or testimony) by process or other reasonable means.

A declarant is not unavailable as a witness if exemption, refusal, claim of lack of memory, inability, or absence is due to the procurement or wrongdoing of the proponent of a statement for the purpose of preventing the witness from attending or testifying.

FED. R. Evid. 804(a). 
above and beyond the expected distress of testifying about painful, personal events. ${ }^{200}$

The proposed requirement that the declarant be proven unavailable or remain available for cross-examination represents a doctrinal departure. Since its inception, the excited utterance exception has not considered the declarant's availability. The theory behind this notion that the excited declarant's availability is immaterial stems from the belief that the declarant can offer no additional insight that would be more valuable to the factfinder than the excited, on-the-spot declaration. By the time of trial, he would be calm, and the testimony of an unexcited live witness is deemed less accurate than the out-of-court excited utterance by the same individual.

This approach, however, not only calls into question the entire premise of the hearsay rule, but it ignores entirely the value of crossexamination. Despite the inability to replicate the on-the-spot excitement (assuming for the sake of argument that the excitement does indeed enhance trustworthiness), cross-examination would be useful to examine important underlying facts. Cross-examination would explore the declarant's excited state, vantage point, ability to perceive events, or possible bias. ${ }^{201}$ Thus, this proposal, which expresses a preference for cross-examination where possible, responds to longstanding criticism of the excited utterance doctrine and injects some good sense and fairuess into the rule. ${ }^{202}$ As a practical matter, the proposal will probably not create a substantial change from current custom. Good trial tactics often dictate a preference for live testimony to buttress out-of-court statements, most available adult declarants do testify.

\section{B. The Survivor's Statement}

Section (b) of the proposed hearsay exception, by far the greater innovation, applies specifically to survivors of rape and other sexual crimes. Most notably, it eliminates all timing requirements. Any statement, no matter how long after the incident, qualifies as a survivor's statement under the proposal if it is made by the survivor and relates to rape or other sexual violence. Such survivor's statements are admissible

200. Cf. Maryland v. Craig, 497 U.S. 836 (1990) (allowing children to testify by closed-circuit television rather than personally confront the defendant if particularized showing is made that the child-witness would experience trauma from face-to-face confrontation with accused).

201. These foundation facts enable the trier of fact to evaluate a declarant's reliability. See Swift, supra note 130 , at 1356-61.

202. In fact, this formulation reflects the request of the petitioner in White v. Illinois, 502 U.S. 346 (1992), who argued that "the Confrontation Clause of the Sixth Amendment requires that ... the prosecution must either produce the declarant at trial or the trial court must find that the declarant is unavailable." Id. at 348-49; see also Seigel, supra note 196 (emphasizing the importance of subjecting available witnesses to cross-examination). 
for the truth of the matters asserted. ${ }^{203}$ They may be offered by the declarant or by others such as rape counselors and friends, who will testify as to what the survivor said concerning the rape or other sexual violence. This new exception eliminates the doctrinal confusion and inconsistency surrounding length of delay under the current excited utterance rule.

More importantly, it remedies a fundamental, substantive flaw in the excited utterance doctrine. The idea of an excited utterance fails to portray accurately a response to stress that is common to survivors of sexual violence. The proposal addresses this problem by admitting survivors' utterances even when they were made significantly after the traumatic event. This recognition that many such survivors delay in reporting the traumatic event comports with not only RTS, but also with the more general (and gender-neutral) tenets of Post-Traumatic Stress Syndrome, upon which RTS is based.

Additionally, the proposed rule does not require that the survivor's state of nervous excitement or shock be proved by independent evidence. ${ }^{204}$ Rape and other sexual violence is stressful enough to qualify without any outward manifestation of nervousness (which according to RTS may be lacking). By focusing on sexual violence, the proposal addresses another doctrinal problem, by reducing the need for judicial determination of whether an event qualifies as "exciting." The exception as proposed could also apply to civil cases (such as where a woman who was raped sues her attacker in tort) but was designed primarily with criminal cases in mind.

The survivor's exception could be adopted without undue hardship on criminal defendants; it nevertheless presents tricky Sixth Amendment issues. Like the proposed revised excited utterance rule, the exception

203. The newly proposed Rule does not limit the use of the survivor's out-of-court statement to rehabilitation. Rehabilitation, a traditional vehicle for admitting a rape survivor's out-of-court statements, allows prosecutors to use rape survivors' out-of-court statements to rehabilitate their credibility only if the honesty or veracity of the rape survivor is challenged by the defendant, something smart defendants avoid doing. See FED. R. EvID. 801(d)(1)(B) (limiting admission of prior consistent statements by witnesses "to rebut an express or implied charge against the declarant of recent fabrication or improper influence or motive"). See generally Christine Kenmore, The Admissibility of Extrajudicial Rape Complaints, 64 B.U. L. REv. 199, 211-15 (1984).

204. Obviously, the trial judge must make a preliminary determination that a triggering violent or sexual event occurred. See FED. R. Evid. 104. The judge need not, however, seek evidence independent of the survivor's statement to make that determination. See Bourjaily v. United States, 483 U.S. 171, 182-83 (1987) (noting that "no independent inquiry into reliability is required when the evidence "falls within a firmly rooted hearsay exception"') (quoting Ohio v. Roberts, 448 U.S. 56, 66 (1980)). Nonetheless, one of the ways that rape victims were traditionally excluded from the excited utterance exception was this requirement of independent evidence of excitement. Wigmore in particular cautioned that rape itself should not be used as evidence of excitement, and independent evidence of stress must be brought in order for a woman's statement to qualify as an excited utterance. See 6 Wigmore, supra note $11, \S 1753$. 
requires the declarant either to testify or to be proven unavailable. Where the declarant-survivor testifies, no objection concerning the defendant's Sixth Amendment right to confrontation arises. Furthermore, the notice requirement protects against any last-minute surprises for the accused. ${ }^{205}$ Where the declarant is unavailable, however, a Sixth Amendment confrontation problem arises, because by definition this new proposal is not "firmly rooted." This triggers a need for the Court to seek "particularized guarantees of trustworthiness"206 to satisfy the Sixth Amendment standard. The trustworthiness requirement in the proposal reflects that constitutional concern.

The trustworthiness requirement also, unfortunately, echoes some retrograde "corroboration" requirements, inviting the accused to attack the survivor's credibility and the judge to weigh the survivor's believability. One can imagine a situation where an unenlightened judge applies the very suspect considerations the proposal was meant to counter: concerns about delay, suspicions about calm demeanor, and general mistrust of women. The trustworthiness finding is necessary, however, given the current state of Sixth Amendment jurisprudence. ${ }^{207}$ Therefore, educating judges about the reasons for a survivor's statement-i.e., that survivors of rape and other sexual violence do not necessarily behave according to the cultural model of the credible witness-becomes a crucial task. Judges must be educated about RTS, but not use it as an absolute measure of credibility. Rather, they need to be educated about the effects of traumatic stress and RTS and the potential for gender bias in fact-finding generally.

This proposal focuses on rape and other sexual violence because most of this Article's discussion of the difference and dominance voices relies on legal and psychological scholarship concerning rape. The Article has relied extensively on RTS for the proposition that the voices and style of communication of women who have experienced sexual violence differ from social expectations. Another benefit of focusing on sexual violence is that there is already a trend in evidence law treating rape and other sexual violence differently from other crimes. One example is the rape shield law; another much more controversial example is the new Federal Rule of Evidence 413, which routinely admits evidence of the accused's similar prior acts in rape cases. ${ }^{208}$ Further-

205. This notice requirement mirrors the recent amendment to Rule 404(b) and the notice requirement in the residual hearsay exception 803(24). See FED. R. Evid. 404(b), 803(24).

206. Idaho v. Wright, 497 U.S. 805, 821 (1990) (citing Roberts, 448 U.S. at 65).

207. Thanks to Myrna Raeder for pointing this out. See Raeder, supra note 165 (delineating a Domestic Homicide Hearsay Exception and requiring that "the circumstances surrounding its making indicate the trustworthiness of the statement").

208. See Aviva Orenstein, A Feminist Critique of Character Evidence and New Rule 413 (unpublished manuscript, on file with California Law Review). 
more, in the tradition of the evidence rules, the proposal is gender neutral. Rape Trauma Syndrome is based on Post-Traumatic Stress Syndrome generally, and there is reason to believe that men experience rape and other sexual violence as traumatic and may, because of shame, exhibit many of the less powerful speaking styles associated with women. ${ }^{209}$

It is fruitful to think about how the proposal might be expanded to include other types of intrusive and domineering behavior. The extension could include stalking, sexual harassment, and other wrongful conduct that induce fear, shame, or post-traumatic stress. More research on the effects of these behaviors and some experience with the rule as more narrowly proposed will inform any future attempts to expand the survivor's exception.

A concern raised by any new exception to the hearsay rule is the effect that it will have on the conduct of a trial. One function of the hearsay rule is to diminish the amount of evidence presented and make trials manageable. What will happen to the length and confusion of a trial if every out-of-court statement made by a rape or other sexual violence survivor comes in? The solution to this administrative problem lies in Rule 403, which allows a trial judge to exclude evidence because of "waste of time" or "needless presentation of cumulative evidence." 210 Statements by the rape or other sexual violence survivor that are merely cumulative are probably excludable under Rule 403 , al-

209. The effects of sexual assault on male survivors are traumatic, and may be quite similar to women's documented reactions to sexual assualt, including shame and denial. See Stuart Turner, Surviving Sexual Assault and Sexual Torture, in Gillian C. Mezey and Michael B. King, Male Victims of SEXUAL ASSAUtT 75 (1992) (arguing that men are likely to engage in the avoidance and denial behavior associated with post-traumatic stress disorder because of their failure to repel their attackers, and because the association of male rape with homosexualtiy and AIDS is too shameful to reveal); Gillian C. Mezey, Treatment of Male Victims of Rape, in id. at 131 (arguing that there is little evidence suggesting that men and women react to sexual assault differently, although some studies have shown that women are more anxious and willing to receive help, and men are more likely to externalize their anger and behave belligerently in the long term); Arthur Kaufman, et al., Male Rape Victims: Noninstitutionalized Assault, 137 AM. J. PsYchIATRY 22I (I980) (comparing 14 male victims with 100 female rape victims and finding that the men were more physically traumatized and were more likely to engage in denial to control their emotions, and less likely to reveal their assaults than the women studied).

210. Federal Rule of Evidence 403 provides:

Although relevant, evidence may be excluded if its probative value is substantially outweighed by the danger of unfair prejudice, confusion of the issues, or misleading the jury, or by considerations of undue delay, waste of time, or needless presentation of cumulative evidence.

FED. R. Evid. 403. The advisory committee note explains that Rule 403 covers risks which range all the way from inducing decision on a purely emotional basis, at one extreme, to nothing more harmful than merely wasting time, at the other extreme. Situations in this area call for balancing the probative value of and need for the evidence against the harm likely to result from its admission.

FED. R. Evid. 403 advisory committee's note. 
though the possibility that a survivor's additional declarations would not affect credibility seems unlikely unless they were truly numerous and entirely redundant. ${ }^{211}$ Alternatively, a judge might exclude a survivor's statement if there is reasonable concern that the jury would confuse various out-of-court statements with live testimony or other admissible statements. This too seems unlikely, given the fact that the survivor will be available to take the stand and the jury will readily be able to distinguish what the survivor currently testifies to and former out-of-court statements. ${ }^{212}$ The potential for unfair prejudice seems greatest where the declarant is unavailable. The added trustworthiness requirement addresses this conceru.

Finally, it is important to note that these proposed reforms are more than just a revival of the prompt complaint doctrine adorned in feuninist garb. ${ }^{213}$ The proposed survivor's statement exception differs from the prompt complaint in four significant ways. First and most obviously, it

211. Commentators wam against over-extension of the "waste of time" prong, which is "a concession to the shortness of life," according to Justice Holmes in Reeve v. Dennett, 11 N.E. 938, 944 (Mass. 1887); see MUEller \& KIRKPATRICK, supra note 24; WRIGHT \& GraHAM, supra note 49, $\S 5211$.

212. Some courts, in debating whether to admit the substance of a rape survivor's prompt complaint, have expressed concern that "repeated iteration" of the survivor's complaint might artificially magnify the evidence and bolster the survivor's testimony unfairly. See State v. Troupe, 677 A.2d 917, 928 (Conn. 1996). The fear is that in reaffirming the admissibility of prompt complaints for the substance as well as the fact of the complaint, the repetitive testimony of various witnesses about the complaints would "lend undue credibility" to the survivor's testimony. Commonwealth v. Licata, 591 N.E.2d 672, 675 (Mass. 1992). Obviously, this Article asserts that, given the suspicion against women and the denial of rape, there is little cliance that evidence of a survivor's statement will overwhelm the jury. Furthermore, any danger of unfair prejudice or confusion could be handled best by Rule 403 . Therefore, admitting the substance of the surivivor's statement is the better result.

213. In fact, many courts have strugglcd with the prompt complaint doctrine, recognizing that the notion that a woman will immediately complain is antiquated, sexist, and empirically wrong. See, e.g., People v. Brown, 883 P.2d. 949, 956 (Cal. 1994) ("Tlie overwhelming body of current empirical stndies, data, and other information establishes that it is not inlerently 'natural' for the victim to confide in someone or to disclose, immediately following commision of the offense, that he or she was sexually assulated."); Licata, 591 N.E.2d at 674 ("We strongly disagree with the notion that a rape victim naturally will complain of an attack soon after it occurs."); State v. Hill, 578 A.2d 370 , 377 (N.J. 1990) (describing the prompt complaint rule as a necessary evil that "serves to neutralize the sexist expectations of some jurors that the woman should have complained after having been raped").

Ultimately, the benefits of admitting prompt complaints trump some courts' unwillingness to endorse the stereotypes underlying the prompt complaint doctrine. In Troupe, for example, the court criticized the prompt complaint doctrine for its assumption that "any 'normal' woman would report a rape soon aftcr its occurrence." 677 A.2d at 924 (quoting State v. Kendricks, 891 S.W.2d 597, 601 (Tenn. 1994)). It nonetheless opined that the presumptions underlying the prompt complaint doctrine still hold sway with jurors, as failure to report still "casts doubt on the credibility of the accusation." Id. at 927. Troupe also illustrates tlie need for a survivor's exception to the excited utterance rule. After an angst-ridden discussion in that case, the Supreme Court of Connecticut scaled-back its policy of allowing substantive use of a prior statement by a rape survivor and reverted to a rule allowing only testimony as to the fact of the complaint. Id. at 923-28. 
eliminates the "promptness" requirement. Learning from RTS that delay in reporting rape and other sexual violence is a normal reaction, it does not require an immediate, first opportunity, or even prompt report. Second, the substance of the survivor's statement is admissible for its truth, unlike a prompt complaint, which is only admissible for the fact that a complaint was made. ${ }^{214}$ Third, the proposed survivor's exception is born out of feminist concern for how women are treated in the courtroom, unlike the prompt complaint requirement, which is rooted in mistrust of women. Rather than perpetuate the notion of an immediate cry (with the ironic twist that the rule of prompt complaint is often perceived to provide a special advantage for women), the proposed survivor's exception actually reflects what we know about how people react to the trauma of sexual attack. Finally, the proposal extends its reach in a gender-neutral fashion, including all who have suffered a violent or sexual crine.

\section{The Practical Effect of the Survivor's Statement}

From a feminist perspective, the greatest conceru must surround the proposal's practical effect on the lives of woinen who report crimes of sex and violence. The history of feminist jurisprudence demonstrates that well-intentioned reforms, born of feminist theory, can sometimes make women's lives harder. ${ }^{215}$ At first blush one might wonder whether the new proposal, which requires available declarants to be subject to cross-examination, might not impose additional hardship, as compared to the current excited utterance, which holds the declarant's availability iinınaterial.

First, because many survivor statements do not fit the current excited utterance exception, many women have lost nothing. Furthermore, as a practical matter, it is hard to imagine a prosecution for rape or any other violent or sexual crime where a survivor, available to testify, would not be called. Certainly the case law involving excited utterances made by survivors of rape and other sexual violence indicates that survivors' extra-judicial statements are generally introduced to supplement the survivors' in-court testimony, not to replace it. ${ }^{216}$ Finally, and most

214. See State v. Grady 183 N.W.2d 707, $715-18$ (Iowa 1971) (distinguishing prompt complaint from excited utterance); State v. Bray, 594 P.2d 1363, I367 (Wash. Ct. App. 1979) (same).

215. See, e.g., Martha Albertson Fineman, The Illusion of Equality: The Rhetoric AND REALITY OF DivorCE REFORM 17-75 (199I) (discussing the negative effects that notions of gender neutrality and equality have had on women's property distributions in divorces, such as under no-fault schemes).

216. My review of the cases indicates that where available, the declarant rape survivor usually testifies. See, e.g., United States v. Dia, No. 93-10592 (9th Cir. 1994) (mem. op.) (citing the "victim's highly credible testimony" and allowing statements made to her roommate under the excited utterance exception); Hacker v. Armontrout, No. 90-0246-CV-W-3, 1990 U.S. Dist. LEXIS I7454 (1990) (habeas petition challenging admission of survivor's testimony regarding statements she made 
problematic from a confrontation perspective, the proposal allows for the possibility that because of injury, intimidation, or emotional trauma the survivor will be deemed unavailable to testify. If such unavailability is proved, the survivor's statement may be admitted as substantive evidence even though the declarant will not be cross examined concerning the statement.

A concern exists about how these proposals will affect young children who are victims of sexual assault and for whom the excited utterance has up until now served as a flexible means of admitting extrajudicial statements to parents, counselors, and doctors. Indeed, the most frequent scenario where the survivor does not testify involves a childvictim. The pattern involves very young children who are deemed by virtue of their age, emotional state, or communication skills to be unable to testify, but whose statements to parents or other supervisory adults are crucial to the case. The proposed survivor's exception would probably serve children well, particularly those deemed unavailable to testify. Children certainly do not seem to fit the pattern of the excited cry, particularly when they know the abuser. They may not fully comprehend the inappropriateness of sexual contact, or may fear reprisal. ${ }^{217}$ The need for hearsay in cases involving children who survive abuse is often

during the rape); Harmon v. Anderson, 495 F. Supp. 341 (E.D. Mich. 1980) (rape victim's testimony supplemented by evidence of excited statement she made to parties from whom she sought help immediately after the rape). It is not always clear from an opinion whether the declarant of an excited utterance was subject to cross examination at trial. Where the record is clear that an adult rape survivor did not testify, the main reason for failure of the survivor to testify is that she did not survive. See, e.g., United States v. Hartmann, 958 F.2d 774 (7th Cir. 1992); Webb v. Lane, 922 F.2d 390, 392 (7th Cir. 1991); United States v. Valentzas, 1993 WL 37339 (E.D.N.Y., Feb. 5, 1993); Sklar v. Ryan, 752 F. Supp. 1252 (E.D. Pa. 1990).

Sometimes problems arise with the in-court testimony. See, e.g., Stephens v. California, No. C92-20204 RMW, 1993 U.S. Dist. LEX1S 10727 (victim testified to memory loss because of alcohol induced blackout and stated that she did not want to testify against a family member). Occasionally, the testimony is vital because the witness, though physically available, will not be of much use to the prosecution. See, e.g., Mitchell v. Mass, No. 94-35220, 1994 U.S. App. LEXIS 25499 (9th Cir. 1994) (mem. op.) (allowing excited utterance of rape victim reported by witnesses where victim was incarcerated in mental hospital for severe psychosis at time of trial); People v. Soto, $35 \mathrm{Cal}$. Rptr. $2 \mathrm{~d}$ 846 (1994) (admitting excited utterance to daughter and neighbors where victim, an elderly woman, suffered totally debilitating stroke after attempted rape). Occasionally, a rape survivor's excited utterance is used when the woman recants her testimony. See, e.g., United States v. Haner, FR074. 48-8033, 1996 WL 520968 (A.F.Ct. Crim. App. Sept. 8. 1996) (conviction upheld where wife's excited utterance admitted to prove rape despite her testimony that husband engaged in consensual sadomasochistic sex).

By contrast, in cases involving children, the main reason for lack of cross examination was the children's incompetence. See White v. Illinois, 502 U.S. 346 (1992) (four-year-old who was sexually assaulted and experienced emotional difficulty left court without testifying); Byrd v. Blodgett, 985 F.2d 571 (9th Cir. 1993) (unpublished table decision); Gregory v. State, 900 F.2d 705, 705 n.1 (4th Cir. 1990) (trial court found child "could not intelligibly express what had happened").

217. See Cynthia J. Hennings, Accommodating Child Abuse Victims: Special Hearsay Exceptions in Sexual Offense Prosecutions, 16 OH1O N.U. L. REv. 663, 670-71 (1989) (discussing the need to protect victims of child abuse from courtroom trauma). 
acute because the child is so frightened and reluctant to testify that incourt testimony seems false or coached, whereas the out-of-court, matter-of-fact statement by the child has the ring of truth. ${ }^{218}$

This proposal would also address much of the criticism that courts extend the excited utterance exception inappropriately, stretching the doctrine beyond recognition in cases involving child victims. Children raise many special issues, ${ }^{219}$ and this Article will forgo the "lifeboat syndrome" of lumping women and children together. It is undeniable that children receive special treatment, and most would agree that they deserve it, but more study of children's reaction to violence, particularly sexualized violence, is necessary to draw any firm conclusions on the point.

\section{CONCLUSION}

The feminist critique presented here, an amalgam of difference and dominance feminism, argues that the current excited utterance doctrine is underinclusive and relies on narrow and unconsciously gendered notions of how normal, honest people react to stress. In particular, the excited utterance exception subtly undermines women's credibility by endorsing social expectations and perpetuating legal and cultural norms that conflict with the experiences of survivors of sexual violence. Furthermore, the excited utterance's construct of how trustworthy people behave under stress perpetuates stereotypes that allow society to discredit women and to deny the pervasiveness of rape and other sexual violence in our society.

This Article proposes a new survivor's exception tailored to victims of rape and other sexual violence that reflects the experiences of sexual violence survivors and applies to survivors of rape and other sexual violence without regard to gender. It attempts to respond to the feminist challenge without compromising the rights of criminal defendants, and therefore proposes the increased safeguards of notice, a preference for in-court testimony to maintain the rights of the accused, and, where the survivor is unavailable, a requirement that the circumstances surround-

218. Compare Jackson v. State, 720 S.W.2d 282, 285 (Ark. 1986) (the in-court "testimony of the victim and her little brother was interspersed with agonizing pauses. It may be the most extreme case of witness reluctance and Ieading we have seen."), with State v. Johnson, 639 P.2d 1332, 1333 (Wash. 1982) (describing an out-of-court casual conversation where a young girl asked her father if milk comes out of a penis. She testificd at trial "that defendant told her it was 'milk' that 'came out of the penis,' but she didn't think so 'cause it tasted yucky") overruled on other grounds by State v. Calle, 888 P.2d 155 (Wash. 1995) (en banc).

219. Courts have acknowledged the special issues children raise both in their very flexible applications of excited utterance and in their adoption of special rules for testimony and children's hearsay. See supra notes 59-61 and accompanying text (explaining how court can deem sympathetic children "excited" for weeks to satisfy the doctrinal requirements of the excited utterance). 
ing the out-of-court statement provide a particularized guarantee of trustworthiness.

The analysis invites further exploration of how other disempowered groups (particularly children, the poor, and minority group members of both sexes) react to stress and how, in turn, society perceives their credibility. Additionally, it raises the question of whether the proposed survivor's exception should be expanded to include other crimes besides sexual violence, such as domestic violence, sexual harassment, and stalking. ${ }^{20}$ Finally, this piece invites further feminist analysis of evidence generally, including how the hearsay rule reinforces gender, race, or class discrimination. The assessment of the hearsay rules as rigid, acontextual, and hierarchical must be balanced against the rights of criminal defendants and the practicalities of trial procedure. Achieving an appropriate balance between recognizing the experience of survivors and the rights of criminal defendants, and translating that balance into workable doctrine, present exciting challenges for future scholarship.

220. See Joan M. Schroeder, Using Battered Women Syndrome Evidence in the Prosecution of A Batterer, 76 IowA L. REv. 553 (I991) (arguing that battered women display many of the same behaviors as rape victims). See generally Mahoney, supra note 175 (discussing the myths and cultural stereotypes surrounding battered women). 
. 